\title{
Exploiting a Neutral BODIPY Copolymer as an Effective Agent for Photodynamic Antimicrobial Inactivation
}

Aoibhin A. Cullen ${ }^{a}$, Ashwene Rajagopal ${ }^{a, b}, K^{2}$ atharina Heintz ${ }^{a}$, Andreas Heisec, Robert Murphyc, Igor V. Sazanovich $^{d}$, Gregory M. Greetham ${ }^{d}$, Michael Towrie ${ }^{d}$, Conor Long ${ }^{a}$, Deirdre Fitzgerald-Hughes ${ }^{b *}$, Mary T. Pryce ${ }^{a *}$

a School of Chemical Sciences, Dublin City University, Dublin 9, Ireland.

b Department of Clinical Microbiology, Royal College of Surgeons in Ireland, RCSI Education and Research, Beaumont Hospital, Beaumont, Dublin 9, Ireland.

c. Department of Chemistry, RCSI University of Medicine and Health Science, 123 St. Stephen's Green, Dublin 2, Ireland, Science Foundation Ireland (SFI) Centre for Research in Medical Devices (CURAM),

The Science Foundation Ireland (SFI) Advanced Materials and Bioengineering Research Centre (AMBER),

d Central Laser Facility, Science \& Technology Facilities Council, Research Complex at Harwell, Rutherford Appleton Laboratory, Didcot, OX11 0QX, UK.

\section{Table of Contents}

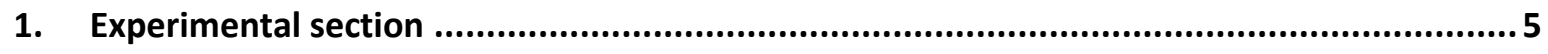

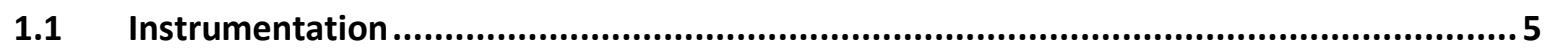

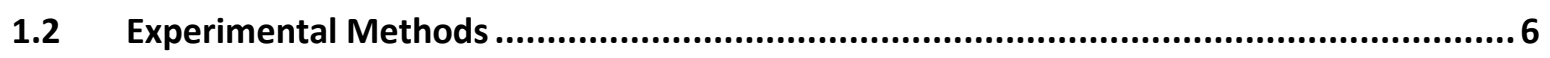

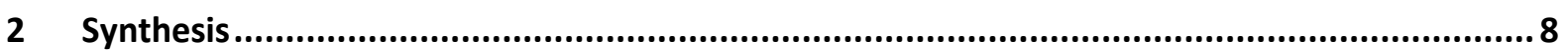

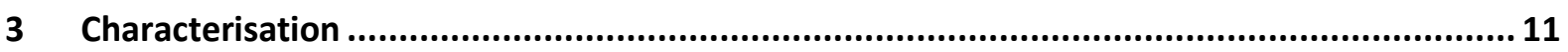

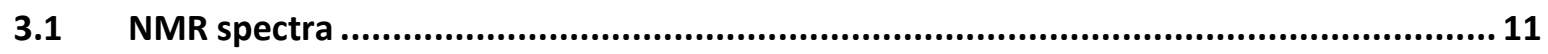

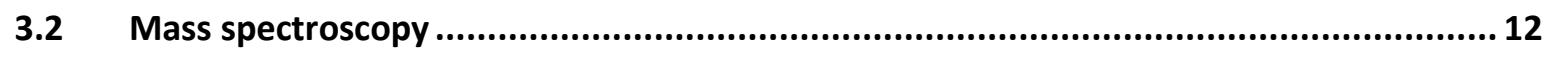

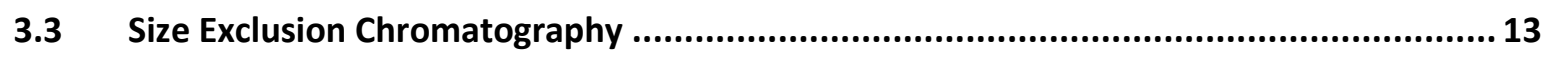

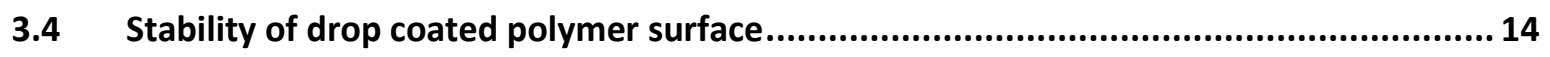

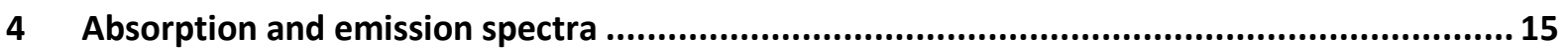

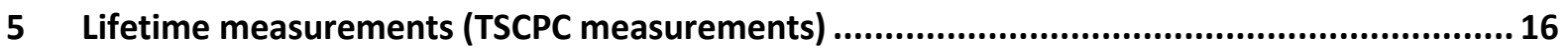

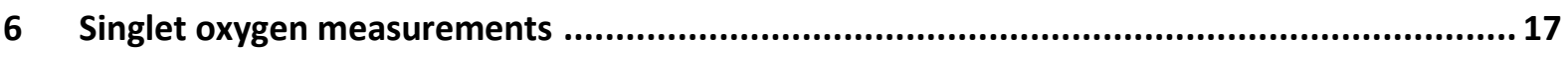

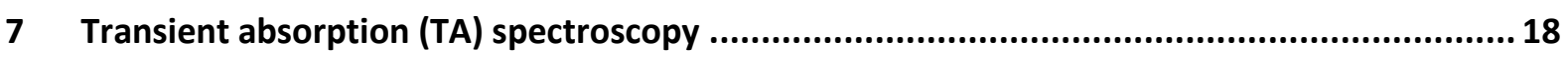




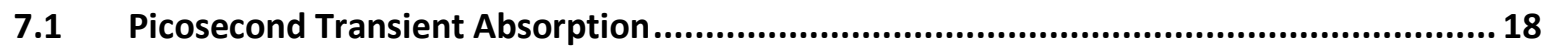

8 FTIR spectra

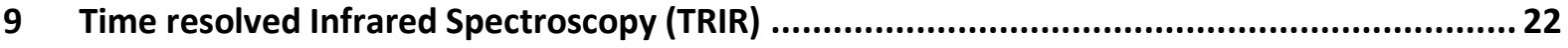

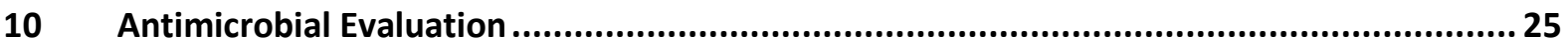

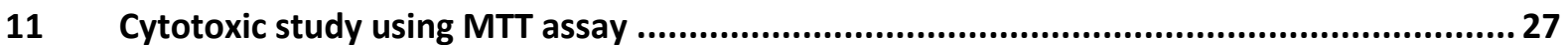

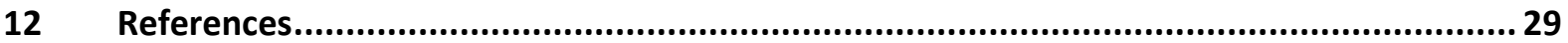




\section{Table of Figures}

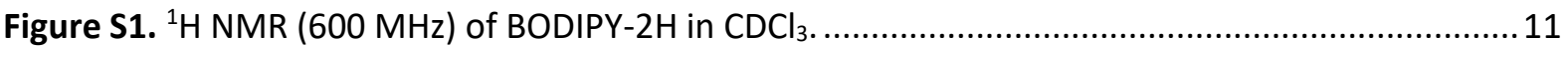

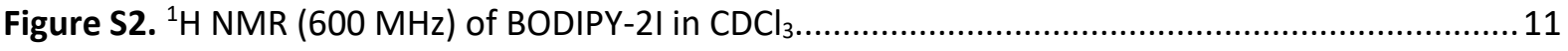

Figure S3. Mass spectra for [M+] for BODIPY-2I, diiodo monomer................................................ 12

Figure S4. Size Exclusion chromatography (SEC) trace of copolymer (dRI detection, PMMA standards).

Figure S5. a) UV-visible spectra of $\mathrm{OH}$ copolymer drop coated onto a cuvette surface. b) SEM image representing the morphology of the $\mathrm{OH}$ copolymer when drop coated on a surface.

Figure S6. a) UV-visible absorption spectra of copolymer in a range of solvents; dichloromethane (solid magenta), DMSO (solid blue), THF (solid red), toluene (solid cyan), acetone (solid violet), acetonitrile (solid black), chloroform (solid green) and b) Emission spectra of copolymer in same range of solvents, $\lambda_{\text {exc }}=560 \mathrm{~nm}, 15 \mathrm{~nm}$ slit width. Inset shows normalised emission spectra of copolymer. All spectra recorded at room temperature in aerated solution

Figure S7. Emission decay profiles of a) BODIPY-2H in $\mathrm{CH}_{2} \mathrm{Cl}_{2}$, b) copolymer in $\mathrm{CH}_{2} \mathrm{Cl}_{2}, \mathrm{c}$ ) copolymer in $\mathrm{CH}_{3} \mathrm{CN}$ and d) copolymer in DMSO. The $\lambda_{\text {exc }}=510 \mathrm{~nm}$ for all samples, and a detection wavelength of $520 \mathrm{~nm}$ for BODIPY-2H and 610 for the copolymer. All emission decays recorded at room temperature in aerated solution. .16

Figure S8. NIR singlet oxygen emission spectrum of Rose Bengal (red), copolymer (purple), BODIPY-2H (orange) in $\mathrm{CH}_{3} \mathrm{CN}$, following excitation at $525 \mathrm{~nm}$.

Figure 59. a) TA spectra of diiodo monomer (BODIPY-2I) in $\mathrm{CH}_{3} \mathrm{CN}$ shown at indicated time decays in ps and b) corresponding kinetic traces at $430 \mathrm{~nm}$ (blue) and $473 \mathrm{~nm}$ (red). The red line corresponding to the kinetic trace at $473 \mathrm{~nm}$ shows the monoexponential fit used to obtain $S_{1}$ lifetime of halogenated species. As the signal at $473 \mathrm{~nm}$ decays $(\tau=146 \mathrm{ps})$, an additional species grows in at $430 \mathrm{~nm}(\tau=137$ ps). These are assigned to the decay of the BODIPY singlet state and formation of the triplet state which persists beyond the time frame of the experimental set-up. The grey dashed lines on the TA spectra correspond to kinetic traces on the right. The asterisk indicates the isosbestic point at $463 \mathrm{~nm}$. $\lambda_{\text {exc }}=525 \mathrm{~nm}(0.4 \mu \mathrm{J} /$ pulse $)$.

Figure S10. a) TA spectra of copolymer in $\mathrm{CH}_{2} \mathrm{Cl}_{2}$ at various time delays indicated in ps with b) corresponding kinetic traces for ESA feature displayed a $440 \mathrm{~nm}$ (green circles), $460 \mathrm{~nm}$ (blue circles) and $465 \mathrm{~nm}$ (red circles). Fit lines for biexponential function are shown in solid lines with corresponding colour. Grey dashed line on TA spectra indicate the kinetic traces on the right. $\lambda_{\text {exc }}=$ $525 \mathrm{~nm}$

Figure S11. a) TA spectra of $\mathrm{H}$-monomer (BODIPY-2H) in $\mathrm{CH}_{3} \mathrm{CN}$ shown at indicated time decays in ps and b) corresponding kinetic traces at $431 \mathrm{~nm}$ (red) and $545 \mathrm{~nm}$ (grey). The grey dashed lines on the 
TA spectra correspond to kinetic traces on the right which do not decay to the baseline within the timeframe of the experiment. $\lambda_{\text {exc }}=525 \mathrm{~nm}(0.4 \mu \mathrm{J} /$ pulse $)$.

Figure S12. FTIR spectra of 1,4 diethynylbenzene (black), BODIPY-2H (blue), BODIPY-2I (red) and copolymer (green) recorded in dichloromethane solution. Inset displays triple bond region $2400-$ $2000 \mathrm{~cm}^{-1}$

Figure S13. TRIR spectra of copolymer in $\mathrm{CD}_{3} \mathrm{CN}$ in the spectral window of $1610-1290 \mathrm{~cm}^{-1}$ at various time delays following excitation at $525 \mathrm{~nm}$. Arrows display spectral changes observed throughout the course of the experiment.

Figure S14. TRIR spectra of copolymer in DMSO in the spectral window of $1610-1290 \mathrm{~cm}^{-1}$ at various time delays following excitation at $525 \mathrm{~nm}$. Arrows display spectral changes observed throughout the course of the experiment. .22

Figure S15. TRIR spectra of BODIPY-2I in $\mathrm{CD}_{3} \mathrm{CN}$ in the spectral window of $1610-1290 \mathrm{~cm}^{-1}$ at various time delays following excitation at $525 \mathrm{~nm}$. Arrows display spectral changes observed throughout the course of the experiment

Figure S16. TRIR spectra of BODIPY- $2 \mathrm{H}$ in $\mathrm{CD}_{3} \mathrm{CN}$ in the spectral window of $1610-1290 \mathrm{~cm}^{-1}$ at various time delays following excitation at $525 \mathrm{~nm}$. Arrows display spectral changes observed throughout the course of the experiment.

Figure S17. TRIR spectra the copolymer in $\mathrm{CHCl}_{3}$ following pulsed photolysis $\left(\lambda_{\text {exc }}=525 \mathrm{~nm}\right.$ ) in the triple bond spectral region, recorded at various time delays, with arrows indicating the time dependent behaviour of the spectral features. Inset displays the kinetic traces at both $2103 \mathrm{~cm}^{-1}$ and $2073 \mathrm{~cm}^{-1}$ (corresponding to both red and blue dashed lines on spectra) and the biexponential fit (solid red and solid blue line) to obtain the decay lifetimes.

Figure S18. UV-visible absorption spectra of copolymer in a range of solvents; especially depicting the stability of the compound in a DMSO/PBS solvent mixture (cyan colour). .25

Figure S19. Comparison on the photoactivated bactericidal activity of copolymer and its BODIPY-2H, Conditions: Bacterial strains Staphylococcus aureus (MSSA, ATCC 25923), methicillin-resistant S.aureus (MRSA, ATCC 43300), Esherichia.coli (E.coli, ATCC 25922) and an extended spectrum $\beta$ lactamase (ESBL) producing E.coli (CL11), [copolymer/BODIPY-2H] for gram-positive bacteria: $1 \mu \mathrm{g} / \mathrm{ml}$, [copolymer/monomer] for gram-negative bacteria: $5 \mu \mathrm{g} / \mathrm{ml}$, time of irradiation: 15 minutes, wavelength of light for irradiation $\lambda \sim 525 \mathrm{~nm}$. .26

Figure S20. The half maximal inhibitory concentration $\left(\mathrm{IC}_{50}\right)$ curve of $\mathrm{OH}$ copolymer under varied concentration on the keratinocyte HaCaT cells. 28 


\section{Experimental section}

\subsection{Instrumentation}

Steady-state spectroscopy: UV-vis spectra was measured using an Agilent 8453 UV-vis spectrophotometer in a $1 \mathrm{~cm}$ quartz cell using spectroscopic grade solvents. Emission spectra were recorded using the FLS1000 Edinburgh Instruments equipped with a Xe Arc lamp and a visible PMT detector and 1 sec scan rate to accumulate the spectra.

Time-correlated single photon counting (TCSPC): TCSPC lifetimes were carried out using FLS1000 Photoluminescence Spectrometer (Edinburgh instruments), equipped with a $510 \mathrm{~nm}$ variable pulse length diode laser (VPL-510) as the excitation source and a visible PMT-900 detector. All data analysis carried out using Floracle ${ }^{\circledR}$ software. The accuracy of the fit of the decays was judged by chi-squared $\left(\chi^{2}\right)$ and sum of residuals was always $\chi^{2}<1.1$. The fluorescence decay time $(\tau)$ was obtained from the slope of the decay curve. All samples were measured in a $1 \mathrm{~cm} \times 1 \mathrm{~cm}$ quartz cuvette and samples were $<0.2$ at $510 \mathrm{~nm}$ to ensure an optically dilute solution to avoid inner-filter effects.

NMR spectroscopy: ${ }^{1} \mathrm{H}-\mathrm{NMR}$ was recorded on either a Bruker AC $400 \mathrm{MHz}$ or $600 \mathrm{MHz}$ spectrophotometer in $\mathrm{CDCl}_{3}$ and were calibrated according to the deuterated solvent peak.

IR spectroscopy: FTIR measurements were carried out on Perkin-Elmer 2000 FTIR spectrophotometer in a liquid solution cell using spectrophotometric grade dichloromethane.Transient absorption spectroscopy: TA spectra recorded on the ps-ns timescale were measured in the ULTRA facility located in Rutherford Appleton Laboratories, UK. Experimental set-up is reported elsewhere. ${ }^{1}$ ns-TA was recorded using the LP980 Edinburgh Instruments $\left(\lambda_{\mathrm{exc}}=355 \mathrm{~nm}\right)$.

Time resolved Infrared spectroscopy: TRIR spectra were measured in the ULTRA facility located in Rutherford Appleton Laboratories, UK and all experimental parameters as per previously described with the TA measurements.

Scanning electron microscopy (SEM): SEM was performed on a Hitachi S3400n electron microscope electron microscope with a magnification $\times 300 \mathrm{~K}$, resolution $3.0 \mathrm{~nm}$. The samples were mounted on carbon tabs and sputtered with gold coating before the measurement. SEM studies were performed at an acceleration voltage of $20 \mathrm{kV}$. 
Size exclusion chromatography (SEC): SEC was conducted in 1,1,1,3,3,3-Hexafluoro-2propanol (HFiP) using a PSS SECurity GPC system equipped with a PFG $7 \mu \mathrm{m} 8 \times 50 \mathrm{~mm}$ precolumn, a PSS $100 \AA, 7 \mu \mathrm{m} 8 \times 300 \mathrm{~mm}$ and a PSS $1000 \AA, 7 \mu \mathrm{m} 8 \times 300 \mathrm{~mm}$ column in series and a differential refractive index (RI) detector at a flow rate of $1.0 \mathrm{~mL} \mathrm{~min}^{-1}$. The systems were calibrated against Agilent Easi-Vial linear poly(methyl methacrylate) (PMMA) standards and analysed by the software package PSS winGPC UniChrom.

\subsection{Experimental Methods}

Commercial reagents were used as received without further purifications. All reactions were carried out using standard Schlenk techniques. Anhydrous solvents were purchased from Sigma Aldrich ${ }^{\circledR}$. 4-hyroxylmethylbenzaldehyde was purchased from Sigma Aldrich ${ }^{\circledR}$.

Fluorescence quantum yield measurement: Steady-state fluorescence measurements were recorded using the FLS1000 photoluminescence spectrometer. Prior to obtaining the emission spectra, samples were diluted to $\sim 0.2$ abs units at $\lambda_{\text {exc }}$ using the UV-vis spectrometer to inhibit inner-filter effect. The reference compound used was previously reported by Banfi et al. (3-pyridine H-BODIPY, $\Phi_{\mathrm{fl}}=0.62$ in $\mathrm{CH}_{2} \mathrm{Cl}_{2}$ ). ${ }^{2}$ An excitation wavelength of $490 \mathrm{~nm}$ was used for the samples and the standards. A slit width of $2.5 \mathrm{~nm}$ was used for all measurements. The compounds were measured in aerated solution at room temperature. The following formula was used to calculate the $\Phi_{\mathrm{fl}}$ :

$$
\Phi_{f l}=\Phi_{f l}^{s t d} \cdot\left(\frac{I_{f l}^{s a m p l e}}{I_{f l}^{s t d}}\right) \cdot\left(\frac{A^{s t d}}{A^{s a m p l e}}\right)
$$

where $\boldsymbol{I}_{\boldsymbol{f l}}^{\text {sample or std }}$ is the area under the curve of the emission spectra and $\boldsymbol{A}^{\text {sample or std }}$ denotes the absorbance of the sample at $490 \mathrm{~nm}$ prior to sample measurement.

Singlet oxygen quantum yield measurement: All singlet oxygen generation experiments were carried out by recording a near infrared emission (NIR) spectra and were recorded using an Andor InGaAs detector coupled with a Shamrock 163 Spectrograph. The excitation sources were supplied by Thorlabs and the monochromatic line used was a $530 \mathrm{~nm}$ diode laser. All UV spectra were recorded both before and after singlet oxygen measurements and it was ensured the optical density (OD) of the sample was below 0.3 absorbance units at the wavelength of excitation, prior to the sample and standard measurement. Standard and 
sample measurements were run under the same experimental conditions using the same solvent, excitation sources and identical experimental parameters were utilised. All samples were run in aerated solvent at room temperature. Background measurements were carried out before running the samples. The singlet oxygen quantum yields were calculated using the following formula:

$$
\Phi_{\text {sample }}=\frac{\Phi_{\text {ref }}\left(\text { Area }_{\text {sample }} \cdot A b s_{\text {ref }}\right)}{\left(\text { Area }_{\text {ref }} \bullet A b s_{\text {sample }}\right)}
$$

Where $\Phi_{\text {ref }}$ is the singlet oxygen quantum yield of the standard (in the same solvent), Area $_{\text {sample }}$ and Area $_{\text {ref }}$ are the integrated area between $1200-1360 \mathrm{~nm}$ of the phosphorescence of singlet oxygen respectively, $A b s_{\text {ref }}$ and $A b s_{\text {sample }}$ are the absorption of both solutions at $530 \mathrm{~nm}$. Rose Bengal was used as a reference, $\Phi_{\Delta}=0.53$ in ACN. ${ }^{3}$

Lifetime analysis: The numerical procedure towards determining the lifetime of each decay $\left(\tau_{i}\right)$ and the corresponding \% relativity of each lifetime component $\left(B_{i}\right)$ is the MarquardtLevenberg algorithm, ultimately to produce a "goodness of fit", $\chi^{2}$ value:

$$
\chi^{2}=\sum_{k} w_{k}^{2}\left(F_{k}-S_{k}\right)^{2}
$$

where $\chi^{2}$ for each lifetime fit was $\sim 1.2$.

Time resolved kinetic analysis: For TA and TRIR, either decay or growth of bands were fitted using either mono (4) or biexponential fitting (4) using OriginLab ${ }^{\circledR}$ software and $\mathrm{R}^{2}$ value $>0.99$ was obtained for every lifetime reported, using the followed formula for exponential fitting:

$$
\begin{aligned}
& y=y_{0}+A e^{-x / \tau_{1}} \\
& y=y_{0}+A_{1} e^{-x / \tau_{1}}+A_{2} e^{-x / \tau_{2}}
\end{aligned}
$$




\section{Synthesis}

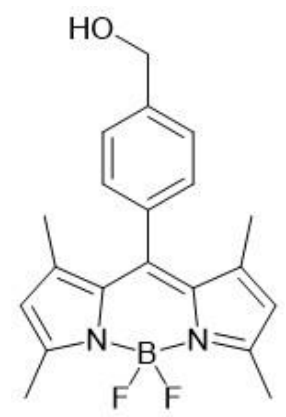

\section{8-(4-Hyroxymethylphenyl)-4,4-difluoro-1,3,5,7-tetramethyl-4-bora-3a,4a-diaza-s-indacene}

(BODIPY-2H, monomer): The synthesis of BODIPY monomers were carried out as previously reported with some minor modifications. ${ }^{4}$ To an oven dried flask fitted with magnetic stir-bar, $25 \mathrm{~mL} \mathrm{CH}_{2} \mathrm{Cl}_{2}$ was added and allowed to purge with $\mathrm{N}_{2}$ for $15 \mathrm{~min}$. To the degassed solvent, aldehyde $(2.5 \mathrm{mmol})$ and 2,4-dimethylpyrrole $(0.51 \mathrm{~mL}, 5.0 \mathrm{mmol})$ were added. A few drops of TFA was added and the solution was stirred overnight at room temperature, in the absence of light. DDQ $(2.48 \mathrm{mmol})$ was added and the solution was continuously stirred for further $4 \mathrm{~h}$. After this time, boron trifluoride diethyl etherate (18.4 mmol) was added, following in quick succession by TEA (41 mmol). The reaction was stirred overnight at room temperature under a continuous flow of nitrogen. Then the reaction was stopped, and the organic layer was collected after washing three times with saturated sodium bicarbonate solution. The organic layer was collected and dried over magnesium sulphate to yield a dark purple crude product. Purification was carried out using column chromatography with on silica (hexane: ethyl acetate $70: 30$ ) to yield a red solid. ${ }^{1} \mathrm{H}$ NMR $\left(600 \mathrm{MHz}, \mathrm{CDCl}_{3}\right): \delta 1.37(\mathrm{~s}, 6 \mathrm{H}), 1.80$ (broad s, $\left.1 \mathrm{H}\right), 2.55$ (s, $6 \mathrm{H}), 4.81(\mathrm{~s}, 2 \mathrm{H}), 5.97(\mathrm{~s}, 2 \mathrm{H}), 7.27(\mathrm{~d}, 2 \mathrm{H}, \mathrm{J}=8.2 \mathrm{~Hz}), 7.49(\mathrm{~d}, 2 \mathrm{H}, \mathrm{J}=8.2 \mathrm{~Hz}) .{ }^{13} \mathrm{C} \mathrm{NMR}\left(600 \mathrm{MHz}, \mathrm{CDCl}_{3}\right)$ : $\delta 14.5,14.6,64.8,121.2,127.4,128.2,131.5,134.2,141.5,141.9,143.1,155.5$. NMR data is as per previously reported. ${ }^{5,6}$ 


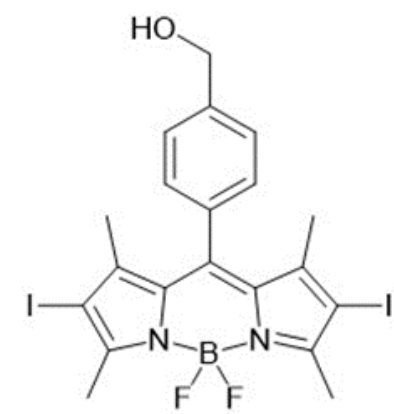

2,6-diiodo-8-(4-Hyroxymethylphenyl)-4,4-difluoro-1,3,5,7-tetramethyl-4-bora-3a,4a-diaza-sindacene (BODIPY-2I, diiodo monomer): This procedure was carried out as per previous reported with some minor modifications. ${ }^{2}$ BODIPY monomer $(0.26 \mathrm{mmol})$ and lodine $(76 \mathrm{mg}, 0.30 \mathrm{mmol})$ were added to an oven-dried round bottom flask equipped with stir-bar, dissolved in $30 \mathrm{~mL}$ of EtOH and purged for $30 \mathrm{~min}$ with nitrogen. lodic acid (93 mg, $0.53 \mathrm{mmol}$ ) was dissolved in $1.5 \mathrm{~mL}$ deionised water and allowed to purge with nitrogen for $30 \mathrm{~min}$. After that, both solutions were combined and allowed to reflux at $60^{\circ} \mathrm{C}$ for $20 \mathrm{~min}$. The solvent was removed using distillation, followed by dissolving the crude product in $\mathrm{CH}_{2} \mathrm{Cl}_{2}$ and washing three times with saturated sodium thiosulphate solution. The organic layer was collected, and the product was dried using rotary evaporation to yield pure product. ${ }^{1} \mathrm{H}$ NMR $\left(600 \mathrm{MHz}, \mathrm{CDCl}_{3}\right): \delta 1.32(\mathrm{~s}, 6 \mathrm{H}), 1.52$ (broad s, $\left.1 \mathrm{H}\right), 2.58(\mathrm{~s}, 6 \mathrm{H}), 4.77(\mathrm{~s}, 2 \mathrm{H}), 7.18(\mathrm{~d}, 2 \mathrm{H}, \mathrm{J}=8.4 \mathrm{~Hz})$, $7.46(\mathrm{~d}, 2 \mathrm{H}, \mathrm{J}=8.1 \mathrm{~Hz}) .{ }^{13} \mathrm{C} \mathrm{NMR}\left(600 \mathrm{MHz}, \mathrm{CDCl}_{3}\right): \delta 15.0,16.1,63.6,84.6,126.6,126.9,132.8,140.2$, 141.5, 144.3, 144.3, 155.8. MS MALDI-TOF [M]: (m/z) mass observed 605.9640, mass theoretical 605.9762 for $\mathrm{C}_{20} \mathrm{H}_{20} \mathrm{BF}_{2} \mathrm{I}_{2} \mathrm{~N}_{2}$. 


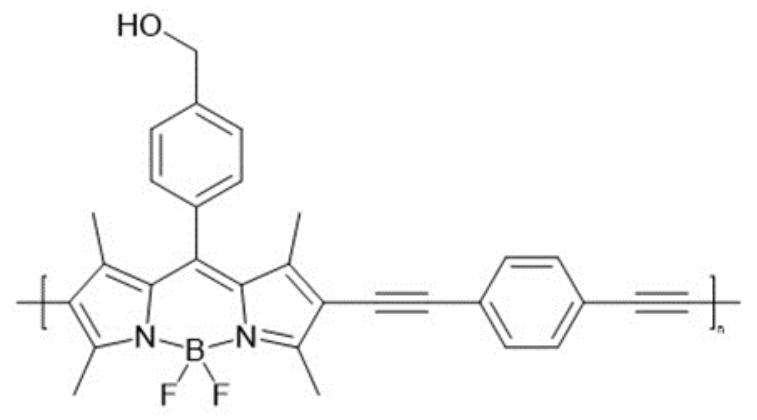

Copolymer: To an oven-dried Schlenk equipped with stir-bar, anhydrous tetrahydrofuran (THF) (15 $\mathrm{mL}$ ) and anhydrous diisopropylamine (DiiPA) $(15 \mathrm{~mL})$ were added. All glass taps were greased and the Schlenk was degassed using three freeze-pump-thaw cycles. Addition of the solids to the Schlenk was then carried out - IODO-BODIPY (0.15 mmol), 1,4-diethynylbenzene (19 mg, $0.15 \mathrm{mmol})$, bis(triphenylphosphine) palladium(II) dichloride (16 mol\%), copper iodide ( $8 \mathrm{~mol} \%)$, triphenylphosphine ( $8 \mathrm{~mol} \%$ ) were added, and the freeze-pump-thaw cycle was repeated to ensure the reaction would occur in the absence of air. The solution was refluxed for $48 \mathrm{hr}$ at $75-85{ }^{\circ} \mathrm{C}$, until complete consumption of the IODO BODIPY was monitored by TLC. After this time, the solvents were removed by distillation. The crude polymer was dissolved in $\mathrm{CH}_{2} \mathrm{Cl}_{2}$ and washed three times with saturated sodium bicarbonate solution. The organic layer was dried over $\mathrm{MgSO}_{4}$. Purification was carried out by washing in $\mathrm{EtOH}$ and collection of the precipitate to yield a pink/purple solid. This process was repeated to yield a pure copolymer free of residual catalytic system. ${ }^{1} \mathrm{H} N M R(600 \mathrm{MHz}$, $\left.\mathrm{CDCl}_{3}\right): \delta 7.69-7.37(\mathrm{br}, \mathrm{Ar}-\mathrm{H}), 4.83\left(\mathrm{br}, \mathrm{CH}_{2} \mathrm{O}-\right), 2.58\left(\mathrm{br}, \mathrm{CH}_{3}\right.$ at 3, 5 position of BODIPY), 1.58 (br, OH as meso position of BODIPY), 1.33 (br, $\mathrm{CH}_{3}$ at 1,7 position of BODIPY). $\mathrm{SEC}$ results: $\mathrm{M}_{n}=11,100, \mathrm{PDI}=$ 1.1. 


\section{Characterisation}

\subsection{NMR spectra}

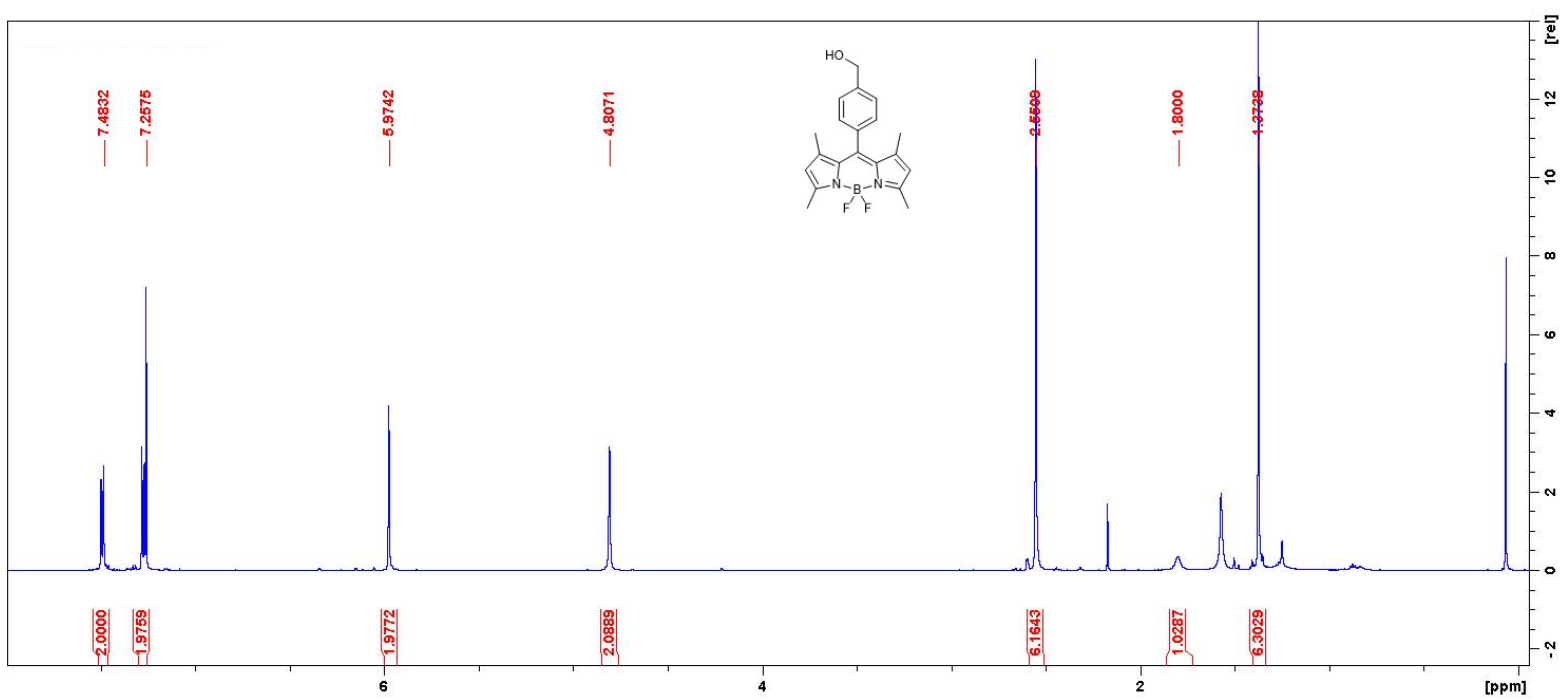

Figure S1. ${ }^{1} \mathrm{H} \mathrm{NMR}(600 \mathrm{MHz})$ of BODIPY-2H in $\mathrm{CDCl}_{3}$.

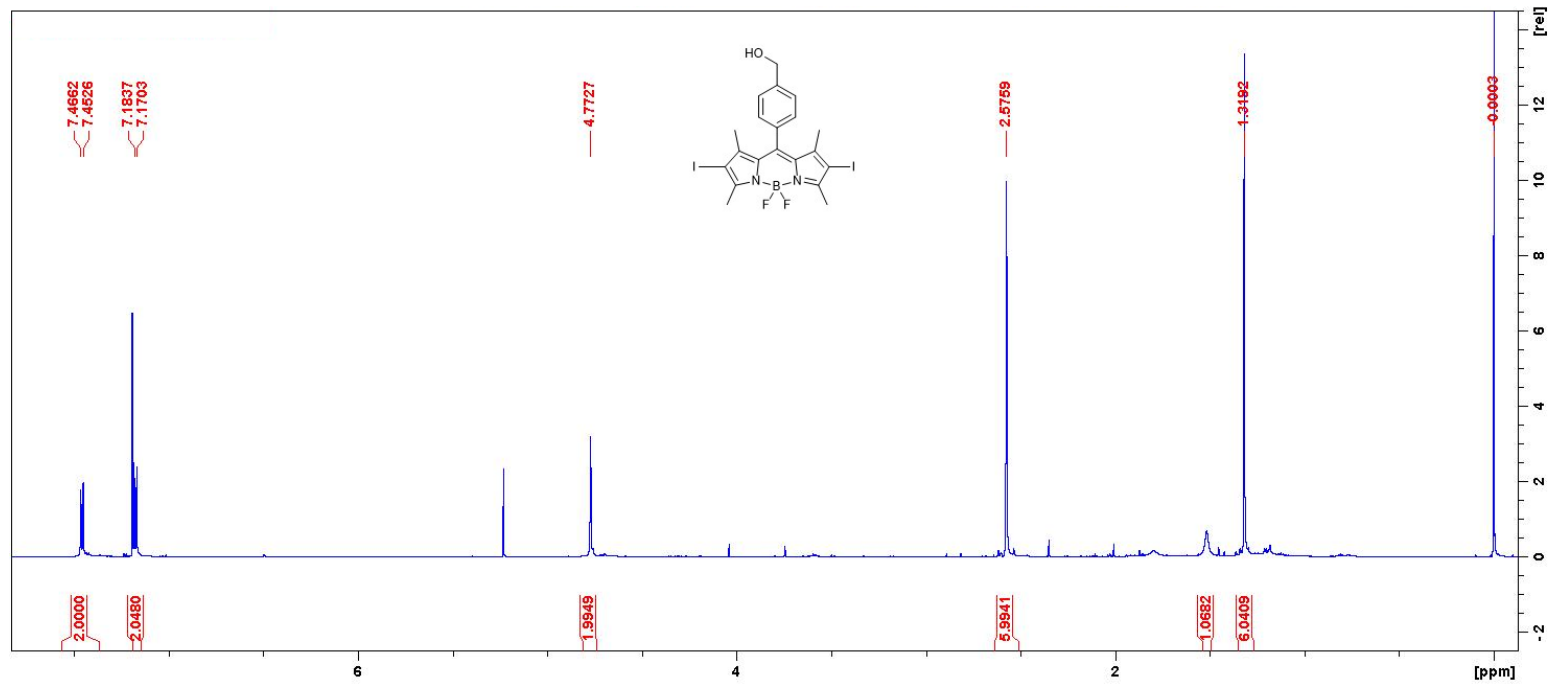

Figure S2. ${ }^{1} \mathrm{H}$ NMR $(600 \mathrm{MHz})$ of BODIPY-2I in $\mathrm{CDCl}_{3}$. 


\subsection{Mass spectroscopy}

Figure: Extracted ion chromatogram (EIC) of compound.

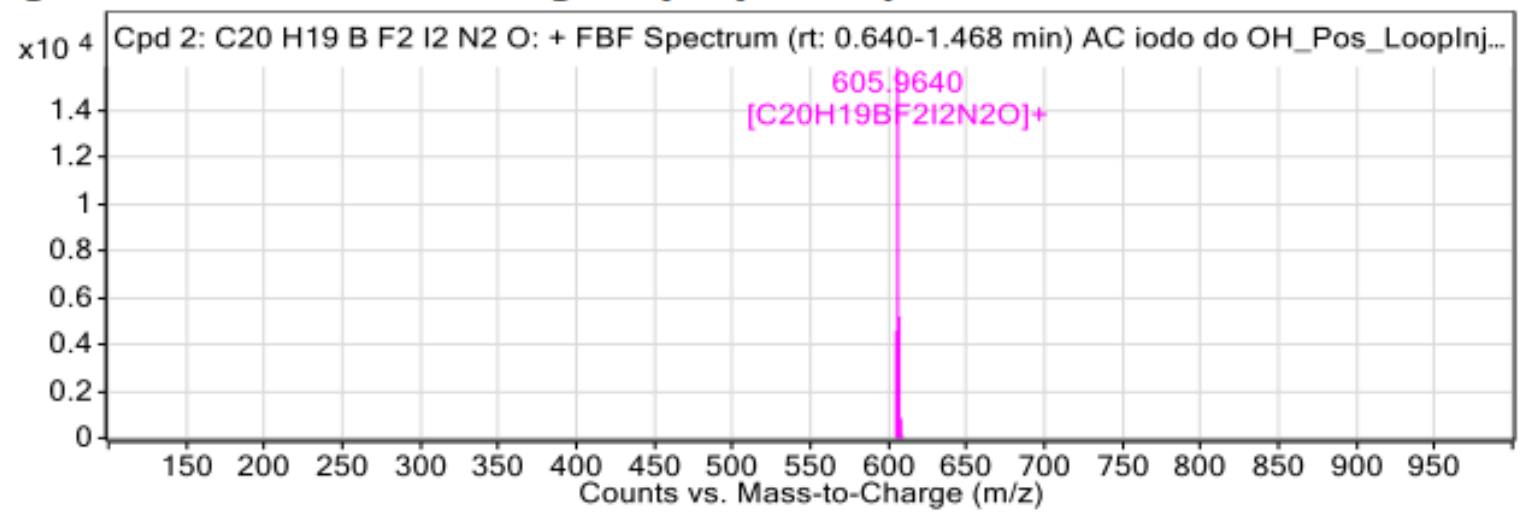

Figure: Full range view of Compound spectra and potential adducts.

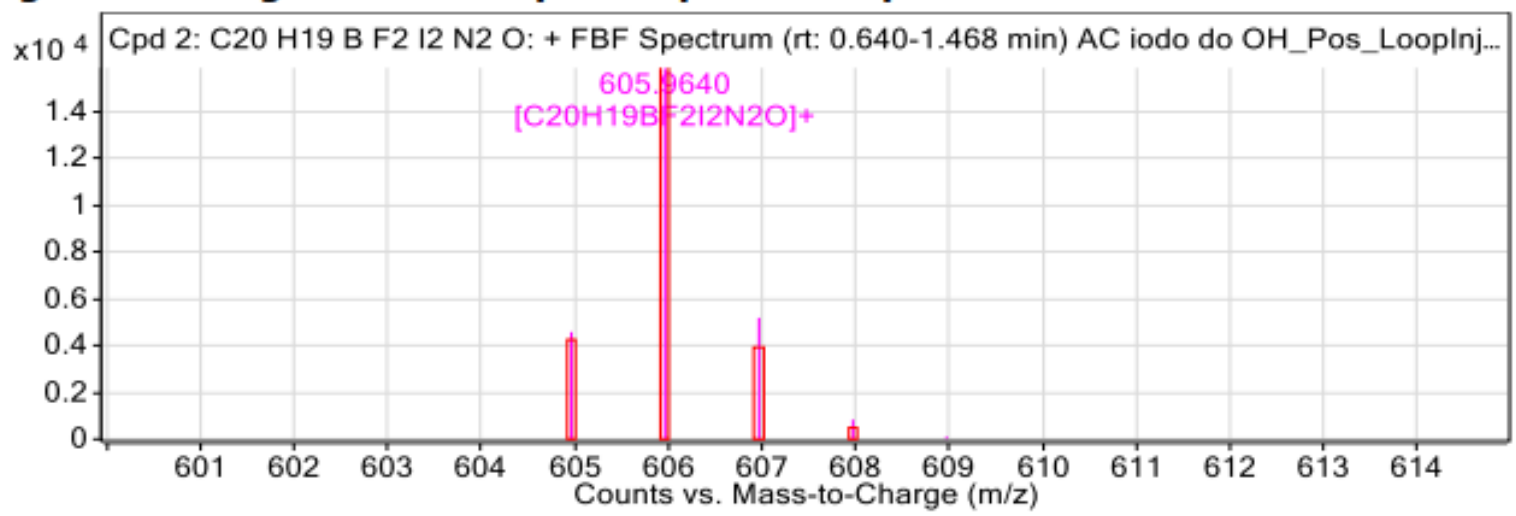

Figure S3. Mass spectra for $\left[\mathrm{M}^{+}\right]$for BODIPY-2I, diiodo monomer. 


\subsection{Size Exclusion Chromatography}

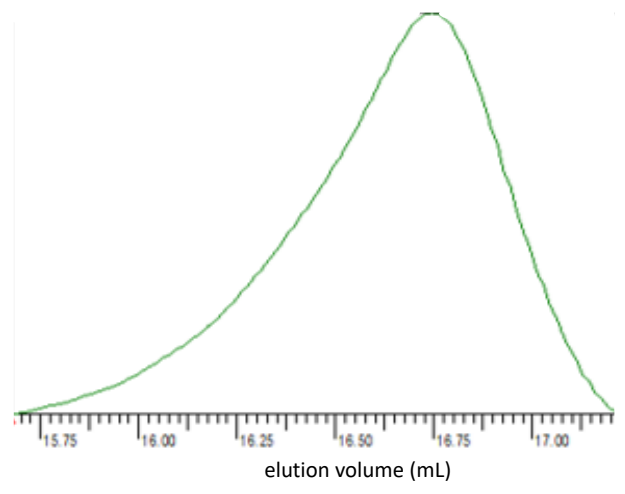

Figure S4. Size Exclusion chromatography (SEC) trace of copolymer (dRI detection, PMMA standards). 


\subsection{Stability of drop coated copolymer surface}

The copolymer was drop coated on a cuvette surface and performed UV-Visible spectroscopy. We could observe that the $\mathrm{OH}$ copolymer spectra is similar in both solution and on solid surface (as shown in Figure S5 (a)) thereby allowing to use the drop coated surface for further antimicrobial studies. Using the scanning electron microscope, we could observe the morphological appearance of the $\mathrm{OH}$ copolymer when drop coated on a carbon surface which is sputter coated with gold. The SEM image (Figure S5 (b)) below show the homogeneous surface of the $\mathrm{OH}$ copolymer where it is unable to see and aggregation or agglomeration formation.

(a)

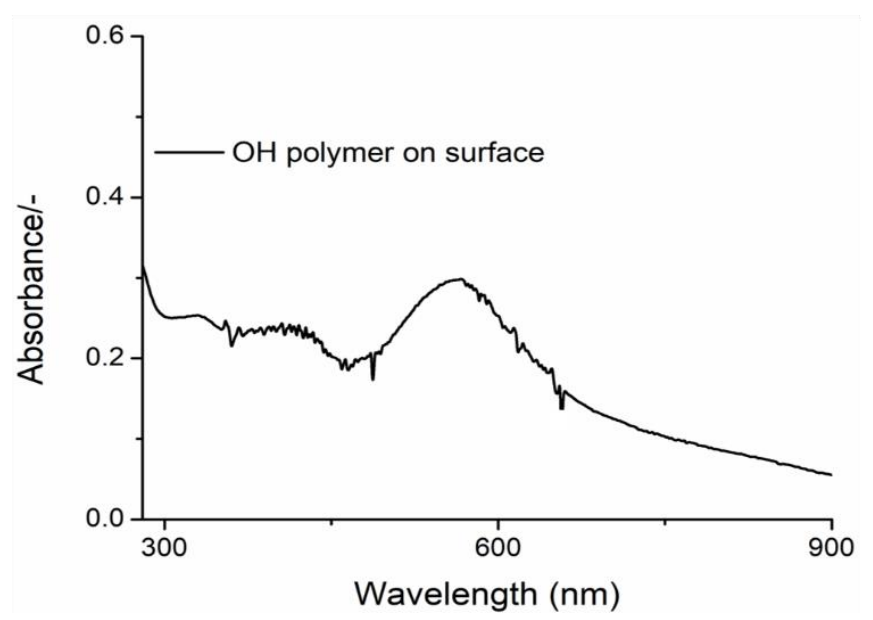

(b)

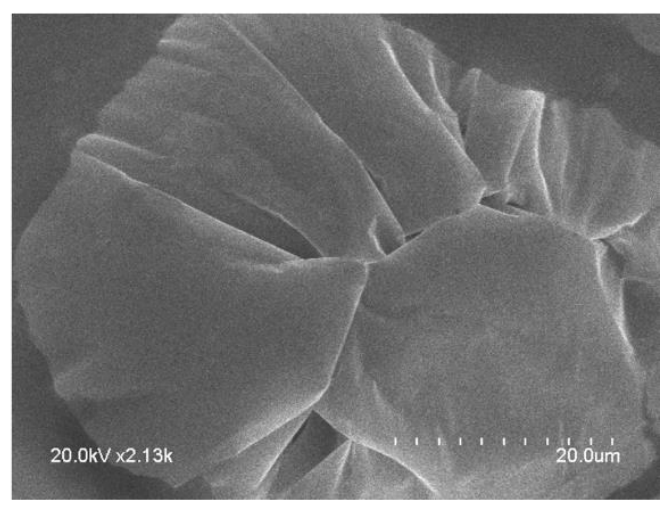

Figure S5. a) UV-visible spectra of $\mathrm{OH}$ copolymer drop coated onto a cuvette surface. b) SEM image representing the morphology of the $\mathrm{OH}$ copolymer when drop coated on a surface. 


\section{Absorption and emission spectra}
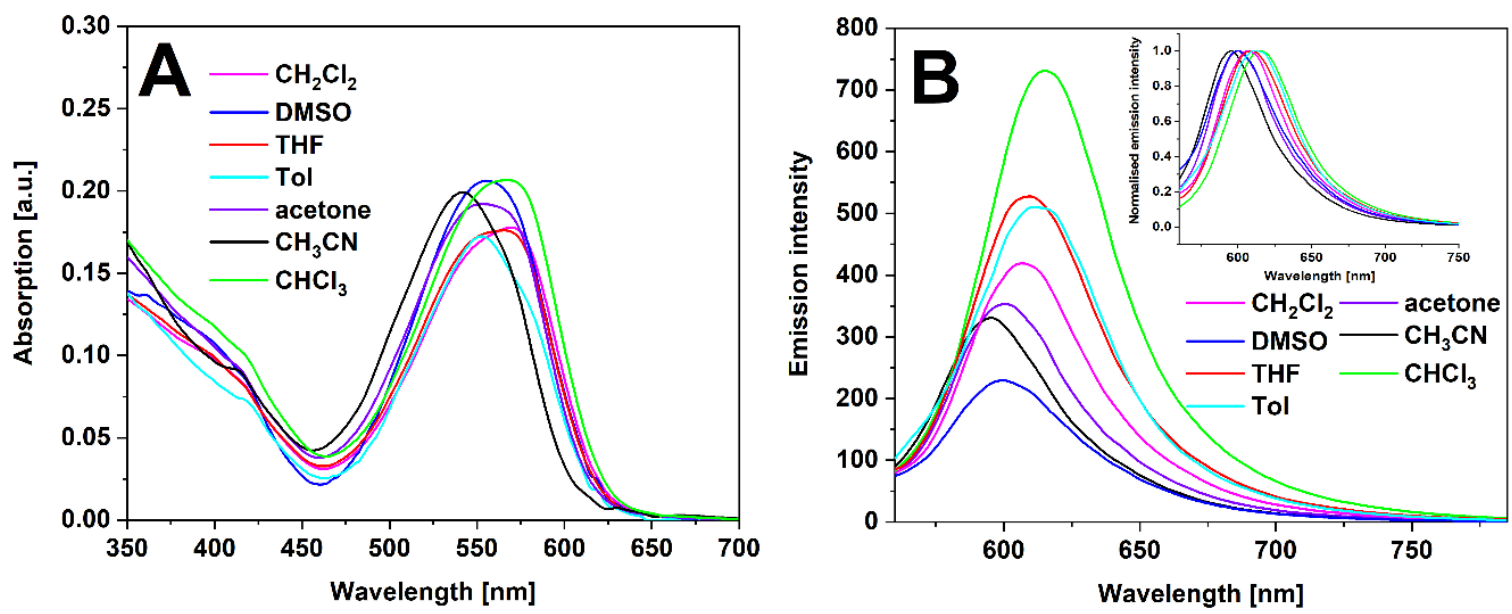

Figure S6. a) UV-visible absorption spectra of copolymer in a range of solvents; dichloromethane (solid magenta), DMSO (solid blue), THF (solid red), toluene (solid cyan), acetone (solid violet), acetonitrile (solid black), chloroform (solid green) and b) Emission spectra of copolymer in the same range of solvents, $\lambda_{\mathrm{exc}}=560 \mathrm{~nm}, 15 \mathrm{~nm}$ slit width. Inset shows normalised emission spectra of copolymer. All spectra recorded at room temperature in aerated solution.

Table S1. Summary of photophysical properties of copolymer analysed in a range of solvents - dichloromethane, dimethyl sulfoxide, THF, toluene, acetone, acetonitrile and chloroform. The Reichardt parameter $\mathrm{E}_{\mathrm{T}}(30)\left(\mathrm{kcal}_{\mathrm{mol}}^{-1}\right)$ is shown beside each solvent in brackets to indicate solvent polarity. ${ }^{7}$ All spectra recorded at room temperature in aerated solution. $560 \mathrm{~nm}$ excitation wavelength was used for emission spectra with $15.0 \mathrm{~nm}$ slit width. All samples were isoabsorptive at the excitation

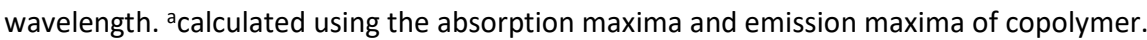

\begin{tabular}{|c|c|c|c|c|c|c|c|}
\hline & & & & Ivent & & & \\
\hline $\mathrm{E}_{\mathrm{T}}(\mathbf{3 0})$ & $\begin{array}{l}\mathrm{CH}_{2} \mathrm{Cl}_{2} \\
(40.7)\end{array}$ & $\begin{array}{l}\text { DMSO } \\
(45.1)\end{array}$ & $\begin{array}{c}\text { THF } \\
(37.4)\end{array}$ & $\begin{array}{c}\text { toluene } \\
\text { (33.9) }\end{array}$ & $\begin{array}{c}\text { acetone } \\
(42.2)\end{array}$ & $\begin{array}{l}\mathrm{CH}_{3} \mathrm{CN} \\
(45.6)\end{array}$ & $\begin{array}{l}\mathrm{CHCl}_{3} \\
\text { (39.1) }\end{array}$ \\
\hline $\begin{array}{l}\lambda_{\text {abs }} \\
(\mathrm{nm})\end{array}$ & 570 & 555 & 565 & 553 & 553 & 542 & 569 \\
\hline$\lambda_{\text {em }}(\mathrm{nm})$ & 607 & 599 & 609 & 611 & 601 & 595 & 615 \\
\hline $\begin{array}{l}\text { Stokes shift } \\
\left(\mathrm{cm}^{-1}\right)^{\mathrm{a}}\end{array}$ & 1069 & 1324 & 1279 & 1717 & 1444 & 1643 & 1315 \\
\hline
\end{tabular}




\section{Lifetime measurements (TSCPC measurements)}
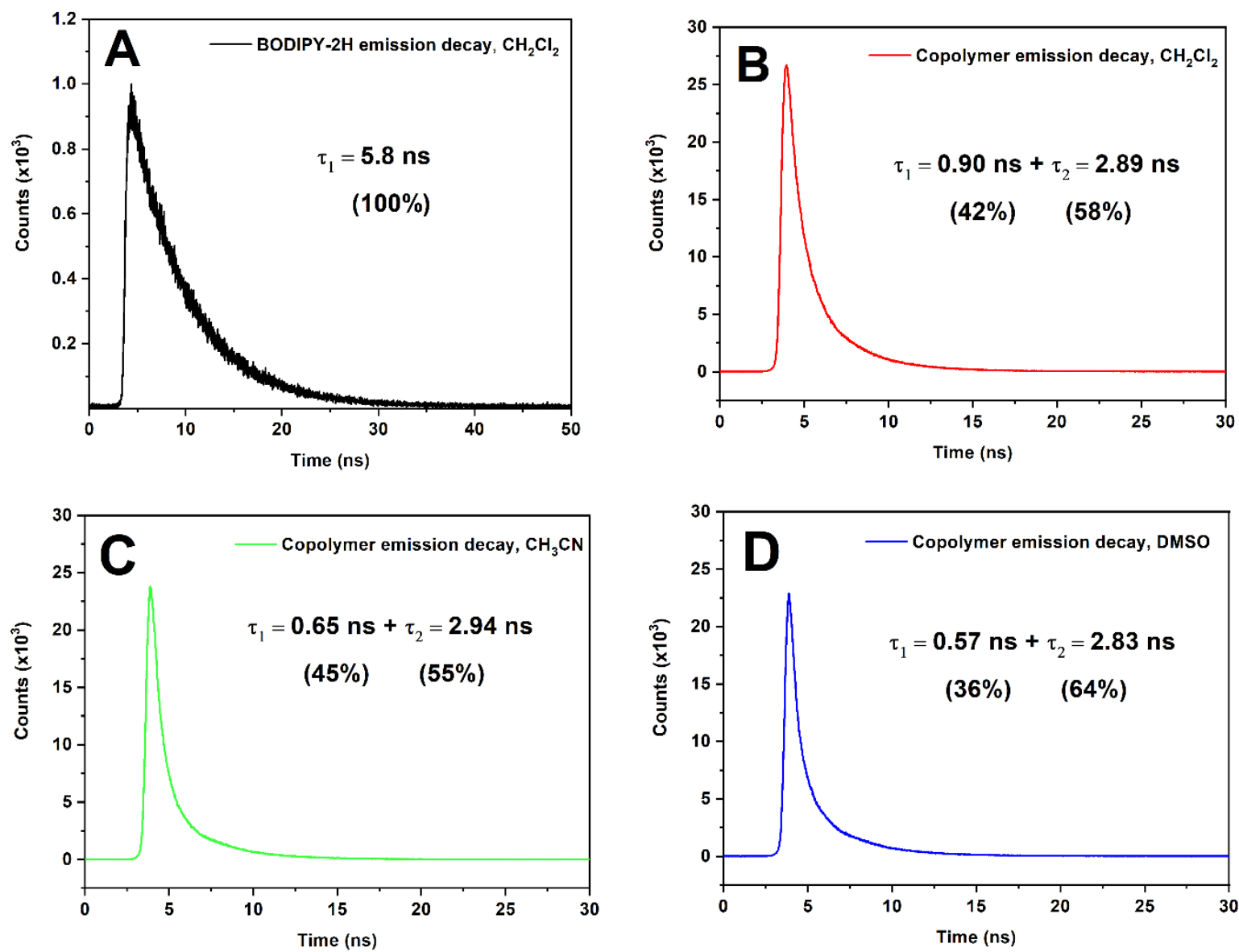

Figure S7. Emission decay profiles of a) BODIPY-2H in $\mathrm{CH}_{2} \mathrm{Cl}_{2}$, b) copolymer in $\mathrm{CH}_{2} \mathrm{Cl}_{2}, \mathrm{c}$ ) copolymer in $\mathrm{CH}_{3} \mathrm{CN}$ and d) copolymer in DMSO. The $\lambda_{\text {exc }}=510 \mathrm{~nm}$ for all samples, and a detection wavelength of $520 \mathrm{~nm}$ for BODIPY-2H and 610 for the copolymer. All emission decays recorded at room temperature in aerated solution.

Table S2. Fluorescence decay lifetimes $(\tau)$ including margin of error associated with each lifetime, \% relativity of each component $\left(\mathrm{B}_{\mathrm{i}}\right)$ for BODIPY-2H in $\mathrm{CH}_{2} \mathrm{Cl}_{2}$ and copolymer in $\mathrm{CH}_{2} \mathrm{Cl}_{2}, \mathrm{CH}_{3} \mathrm{CN}$ and DMSO. $\lambda_{\text {exc }}=510 \mathrm{~nm}$ using FLS1000 photoluminescence spectrometer.

\begin{tabular}{cccccc}
\hline Compound & Solvent & $\tau_{1}(\mathbf{n s})$ & $\mathbf{B}_{1}(\%)$ & $\tau_{2}$ (ns) & $\mathbf{B}_{2}(\%)$ \\
\hline BODIPY-2H & $\mathrm{CH}_{2} \mathrm{Cl}_{2}$ & $5.80+/-0.09$ & 100 & - & - \\
\hline Copolymer & $\mathrm{CH}_{2} \mathrm{Cl}_{2}$ & $0.90+/-0.03$ & 42 & $2.89+/-0.05$ & 58 \\
\hline Copolymer & $\mathrm{CH}_{3} \mathrm{CN}$ & $0.65+/-0.02$ & 45 & $2.94+/-0.05$ & 55 \\
\hline Copolymer & $\mathrm{DMSO}$ & $0.57 \pm 0.02$ & 36 & $2.83 \pm 0.04$ & 64 \\
\hline
\end{tabular}




\section{Singlet oxygen measurements}

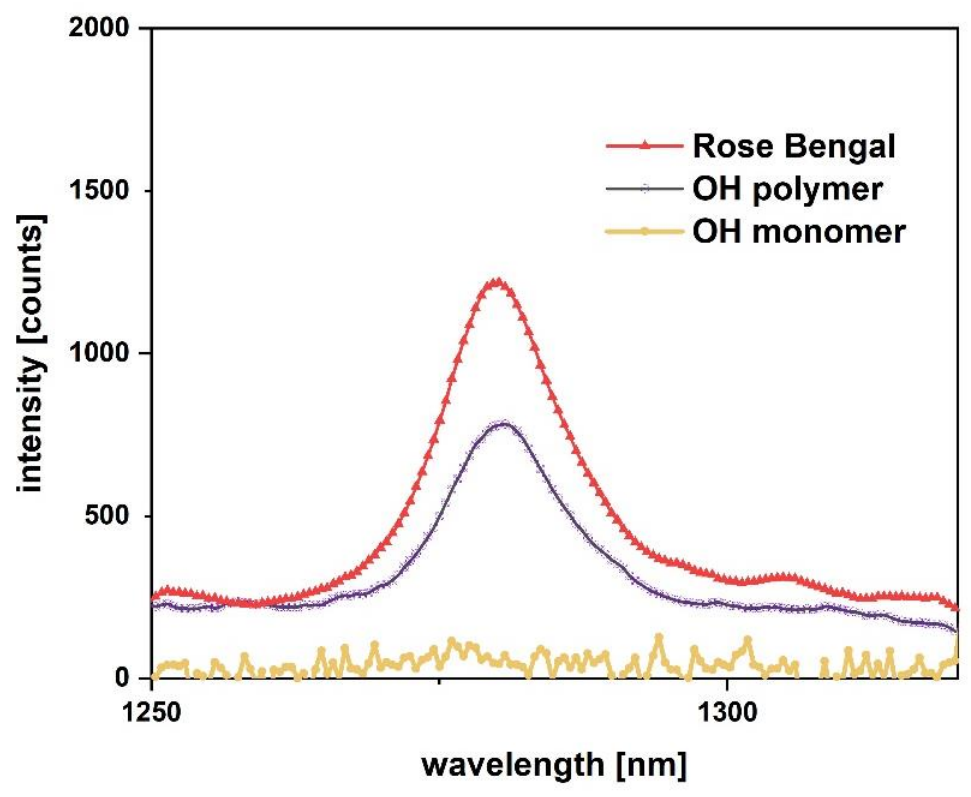

Figure S8. NIR singlet oxygen emission spectrum of Rose Bengal (red), copolymer (purple), BODIPY-2H (orange) in $\mathrm{CH}_{3} \mathrm{CN}$, following excitation at $525 \mathrm{~nm}$. 


\section{Transient absorption (TA) spectroscopy}

\subsection{Picosecond Transient Absorption}
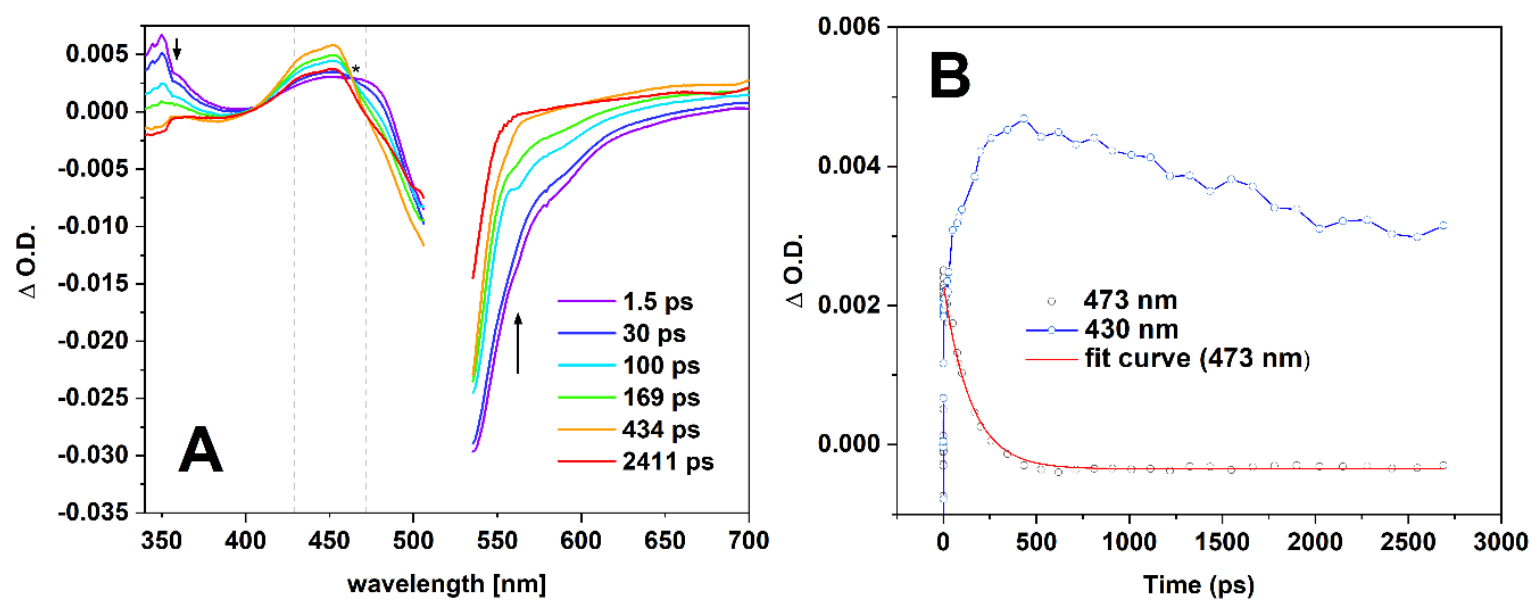

Figure S9. a) TA spectra of diiodo monomer (BODIPY-2I) in $\mathrm{CD}_{3} \mathrm{CN}$ shown at indicated time decays in ps and $b$ ) corresponding kinetic traces at $430 \mathrm{~nm}$ (blue) and $473 \mathrm{~nm}$ (red). The red line corresponding to the kinetic trace at $473 \mathrm{~nm}$ shows the monoexponential fit used to obtain $S_{1}$ lifetime of halogenated species. As the signal at $473 \mathrm{~nm}$ decays $(\tau=146 \mathrm{ps})$, an additional species grows in at $430 \mathrm{~nm}(\tau=137 \mathrm{ps})$. These are assigned to the decay of the BODIPY singlet state and formation of the triplet state which persists beyond the time frame of the experimental set-up. The grey dashed lines on the TA spectra correspond to kinetic traces on the right. The asterisk indicates the isosbestic point at $463 \mathrm{~nm} . \lambda_{\text {exc }}=525 \mathrm{~nm}(0.4 \mu \mathrm{J} / \mathrm{pulse})$.

Table S3. Lifetimes obtained (ps) for the species observed in the diiodo monomer at 472 and $430 \mathrm{~nm}$, corresponding to decay of the singlet, and formation of the triplet state.

\begin{tabular}{lll}
\hline & $\tau_{1}(\mathbf{p s})$ & $\mathbf{R}^{2}$ \\
\hline $\mathbf{4 3 0} \mathbf{n m}$ & $137( \pm 5)$ & 0.99 \\
\hline $\mathbf{4 7 2} \mathbf{n m}$ & $146( \pm 2)$ & 0.99 \\
\hline
\end{tabular}



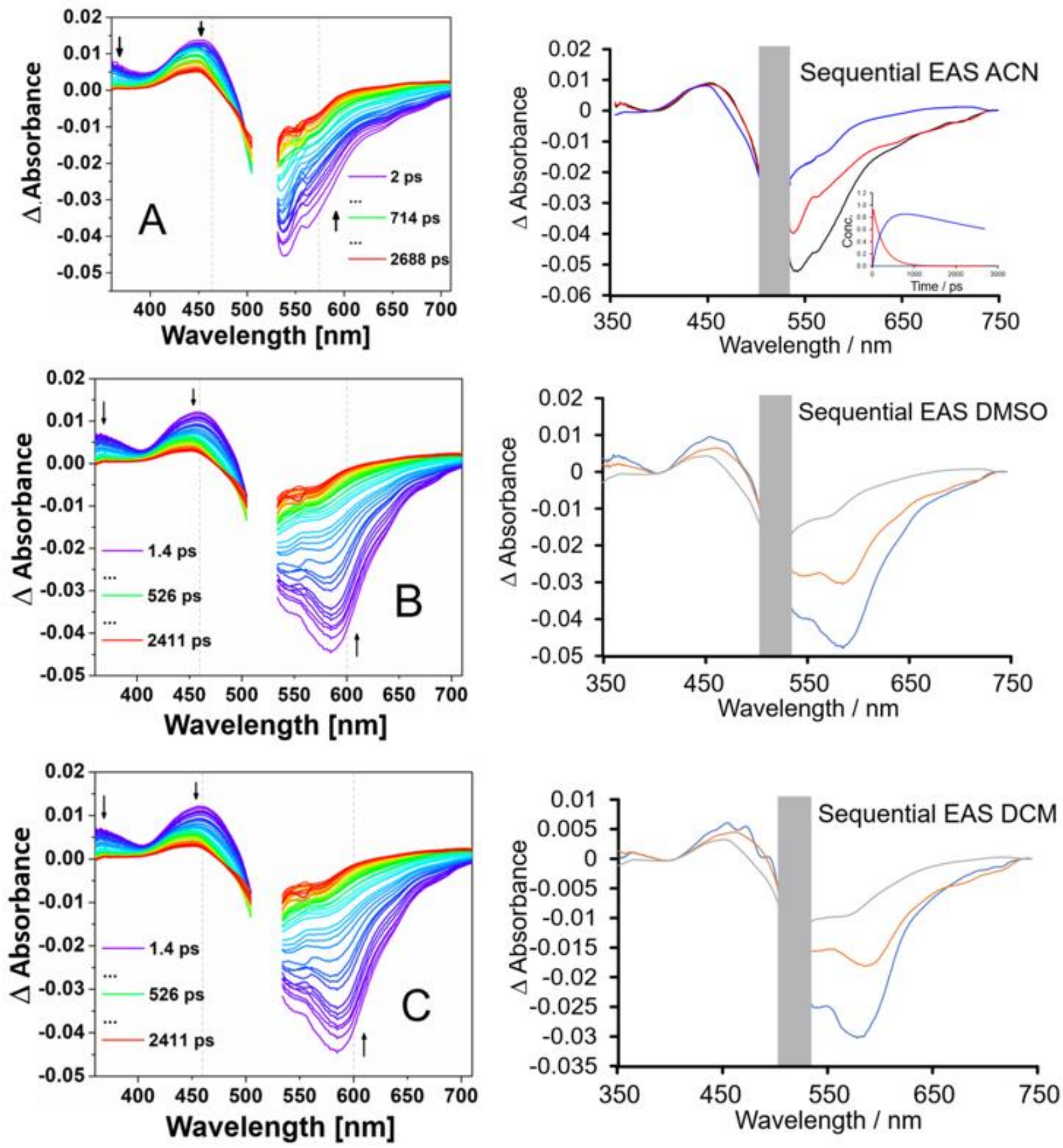

Figure S10. Transient absorption (TA) spectra of the copolymer and corresponding EAS spectra in (A) $\mathbf{d}_{3}$-acetonitrile, (B) $\mathbf{d}_{6}$-DMSO and (C) $\mathrm{d}_{2}$-dichloromethane, following excitation $\left(\lambda_{\text {exc }}=525 \mathrm{~nm}(0.4 \mu \mathrm{J} / \mathrm{pulse})\right.$ (the gap in the TA plots corresponds to the excitation wavelength which is masked by a narrow band pass filter 

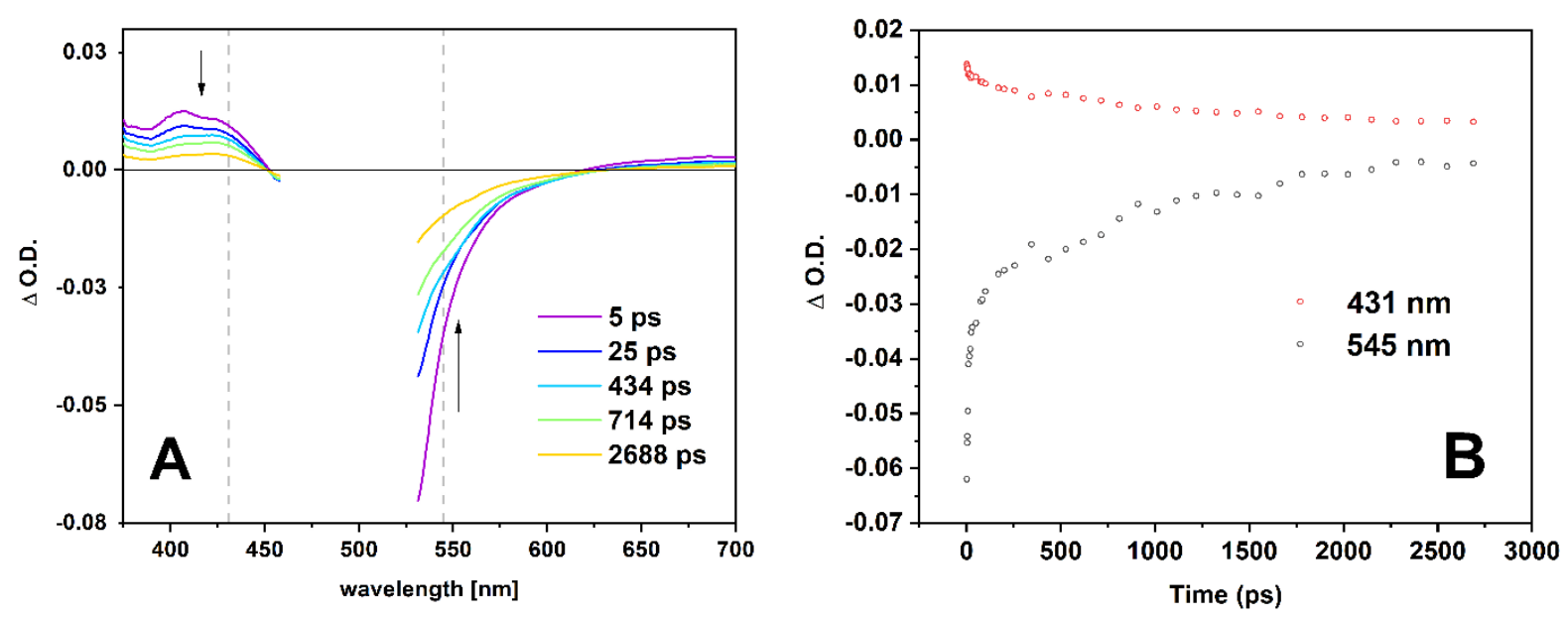

Figure S11. a) TA spectra of $\mathrm{H}$-monomer (BODIPY-2H) in $\mathrm{CH}_{3} \mathrm{CN}$ and b) corresponding kinetic traces at $431 \mathrm{~nm}$ (red) and 545 $\mathrm{nm}$ (grey). The grey dashed lines on the TA spectra correspond to kinetic traces on the right which do not decay to the baseline within the timeframe of the experiment. $\lambda_{\mathrm{exc}}=525 \mathrm{~nm}(0.4 \mu \mathrm{J} / \mathrm{pulse})$.

\subsection{Nanosecond Transient Absorption}

Table S4. Summary of lifetimes obtained $(\mu \mathrm{s})$ of the copolymer from a monoexponential fit of both the ESA feature (446 $\mathrm{nm})$ and GSB feature (524 $\mathrm{nm})$.

\begin{tabular}{lcc}
\hline & $\tau_{1}(\mu \mathrm{s})$ & $\mathbf{R}^{2}$ \\
\hline Acetonitrile & & \\
\hline $\mathbf{4 4 6} \mathbf{n m}$ & $32 \pm 3$ & 0.99 \\
\hline $524 \mathrm{~nm}$ & $29 \pm 2$ & 0.99
\end{tabular}




\section{FTIR spectra}

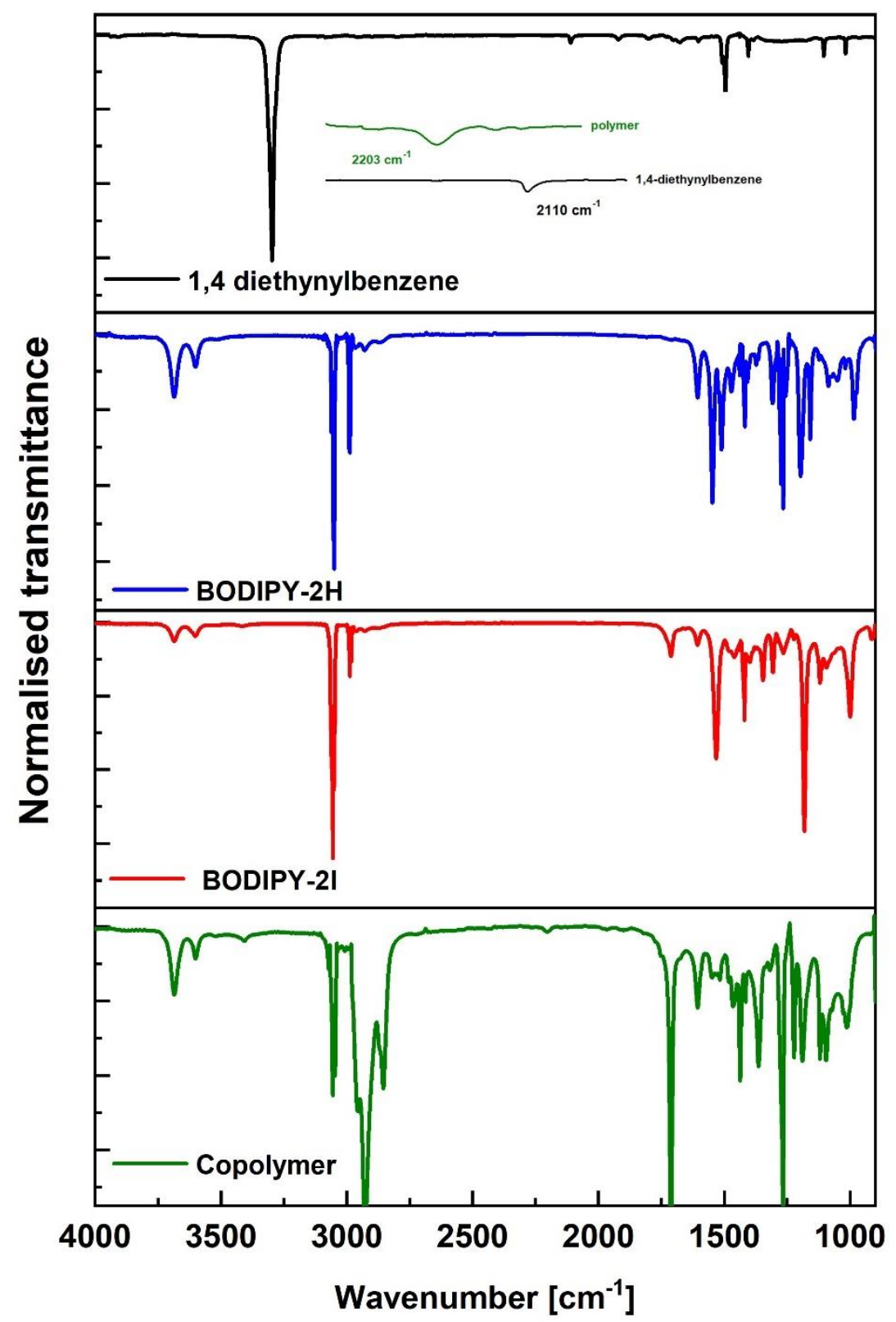

Figure S12. FTIR spectra of 1,4 diethynylbenzene (black), BODIPY-2H (blue), BODIPY-2I (red) and copolymer (green) recorded in dichloromethane solution. Inset displays triple bond region $2400-2000 \mathrm{~cm}^{-1}$. 


\section{Time resolved Infrared Spectroscopy (TRIR)}
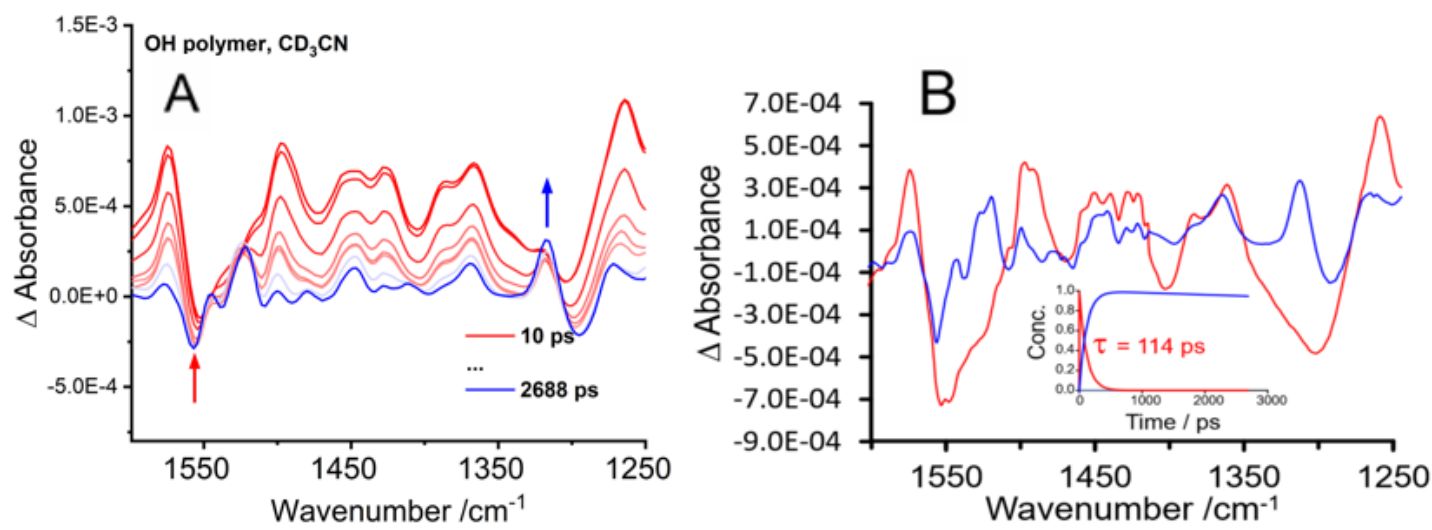

Figure S13. (A) TRIR spectra of the copolymer in $\mathrm{CD}_{3} \mathrm{CN}$ in the spectral window of $1610-1290 \mathrm{~cm}^{-1}$ at various time delays following excitation at $525 \mathrm{~nm}$, and (B) the corresponding EAS.

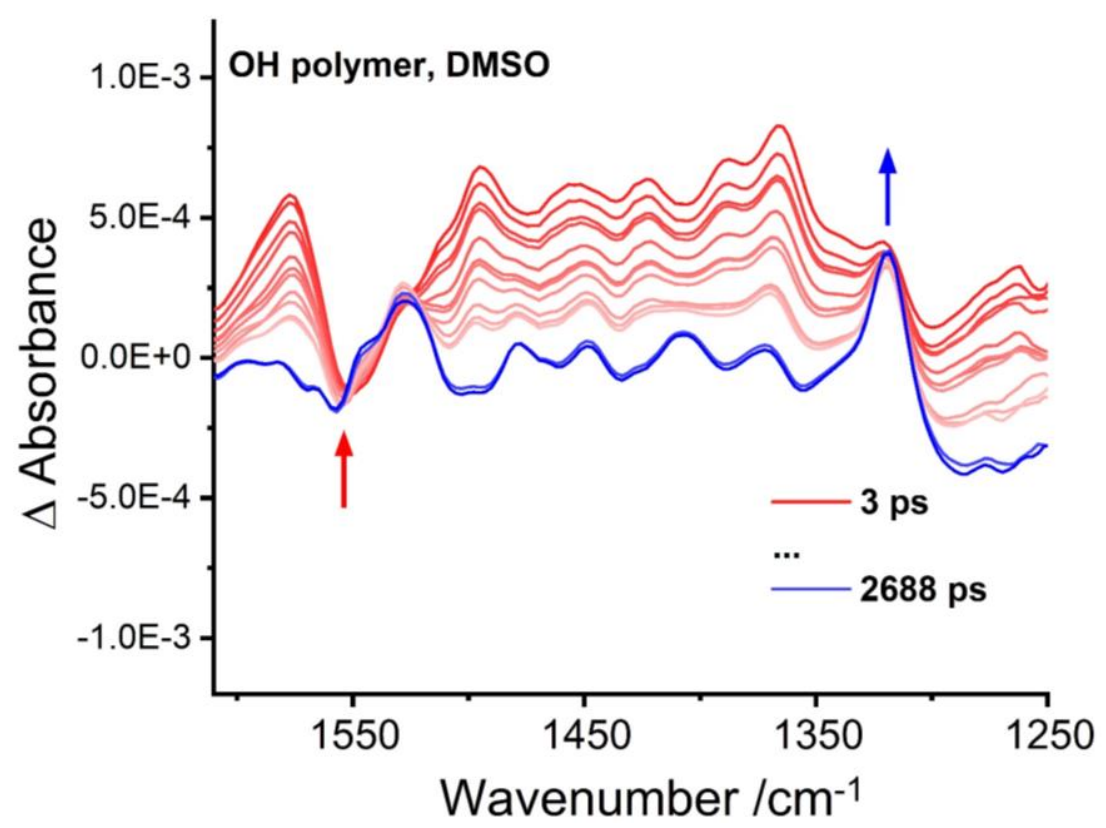

Figure S14. TRIR spectra of copolymer in DMSO in the spectral window of $1610-1290 \mathrm{~cm}^{-1}$ at various time delays following excitation at $525 \mathrm{~nm}$. Arrows display spectral changes observed throughout the course of the experiment. 


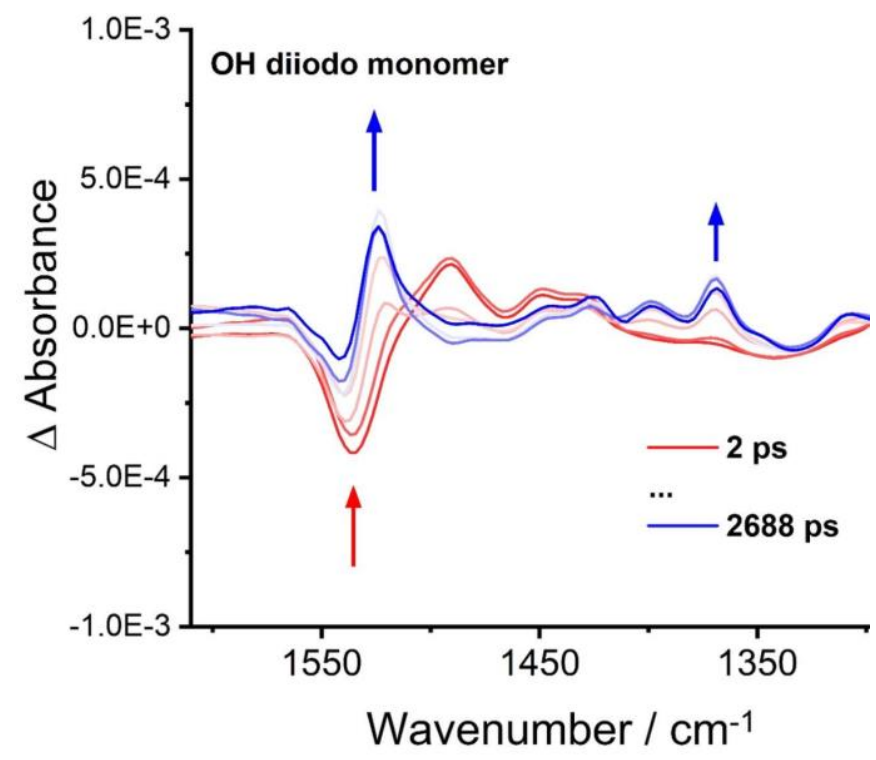

Figure S15. TRIR spectra of BODIPY-2I in $\mathrm{CD}_{3} \mathrm{CN}$ in the spectral window of $1610-1290 \mathrm{~cm}^{-1}$ at various time delays following excitation at $525 \mathrm{~nm}$. Arrows display spectral changes observed throughout the course of the experiment

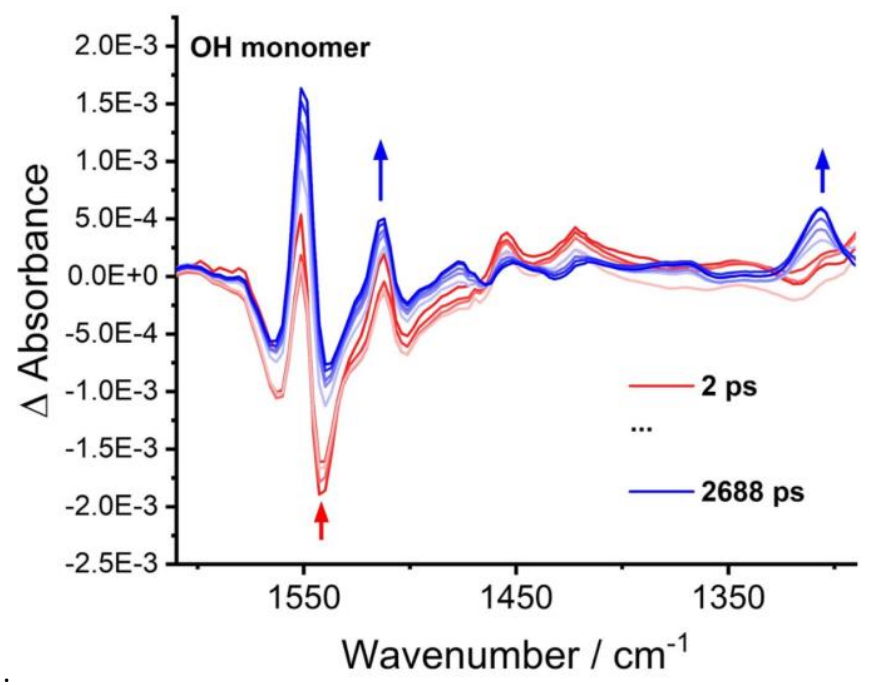

Figure S16. TRIR spectra of BODIPY-2H in $\mathrm{CD}_{3} \mathrm{CN}$ in the spectral window of $1610-1290 \mathrm{~cm}^{-1}$ at various time delays following excitation at $525 \mathrm{~nm}$. Arrows display spectral changes observed throughout the course of the experiment. 


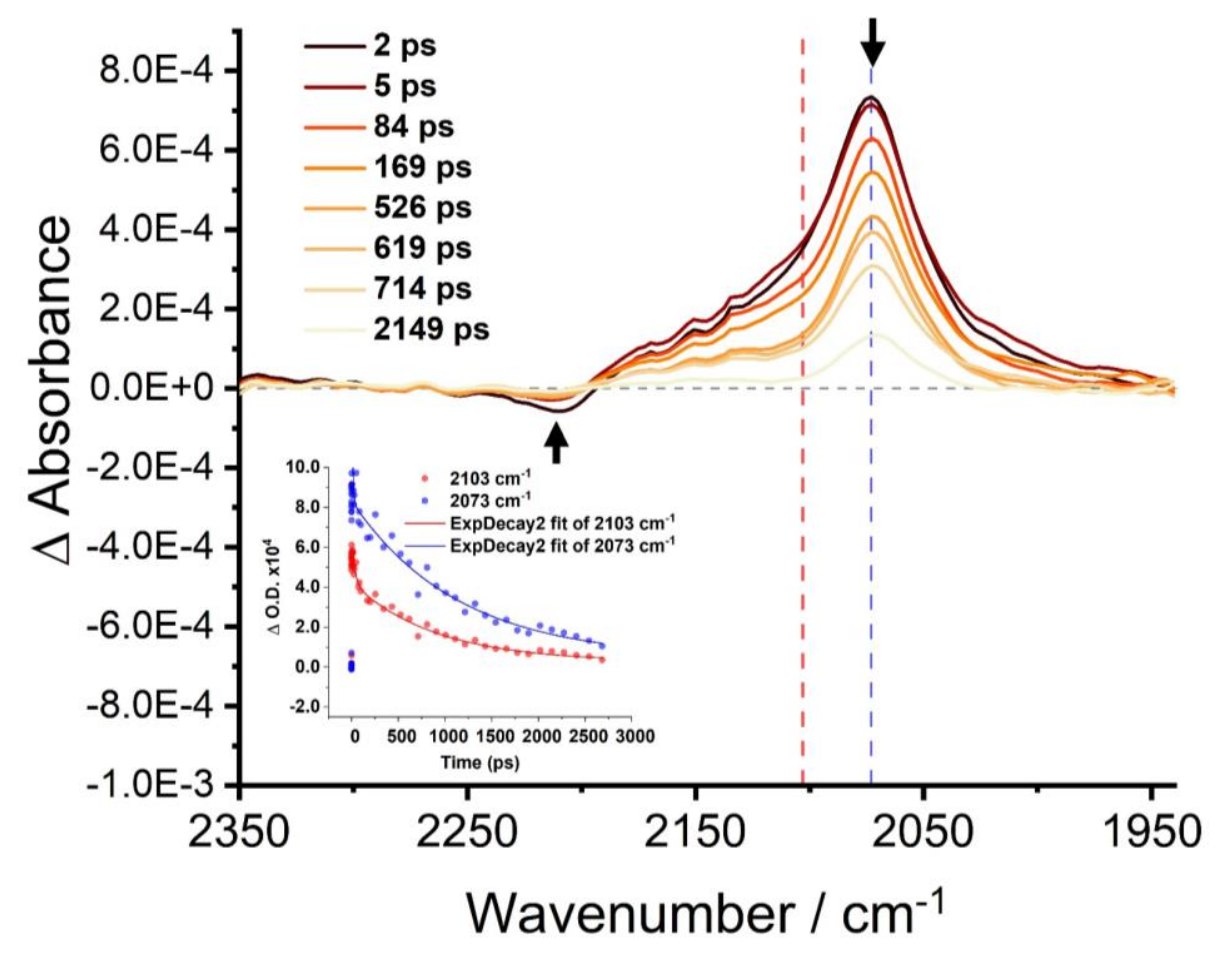

Figure S17. TRIR spectra the copolymer in $\mathrm{CHCl}_{3}$ following pulsed photolysis $\left(\lambda_{\text {exc }}=525 \mathrm{~nm}\right)$ in the triple bond spectral region, recorded at various time delays, with arrows indicating the time dependent behaviour of the spectral features. Inset displays the kinetic traces at both $2103 \mathrm{~cm}^{-1}$ and $2073 \mathrm{~cm}^{-1}$ (corresponding to both red and blue dashed lines on spectra) and the biexponential fit (solid red and solid blue line) to obtain the decay lifetimes. 


\section{Antimicrobial Evaluation}

The antimicrobial activity of the copolymer was assessed using four different reference bacterial strain such as Staphylococcus aureus (S.aureus, ATCC 25923), methicillin-resistant S.aureus (MRSA, ATCC 43300), Esherichia.coli (E.coli, ATCC 25922) and an extended spectrum $\beta$-lactamase (ESBL) producing E.coli (CL11). All the bacterial strains were grown overnight at $37^{\circ} \mathrm{C}$ on Mueller-Hinton (MH) agar and suspensions were prepared from isolated colonies to the density of a 0.5 McFarland standard (bioMèrieux, Ireland) and were further diluted $1 / 100$ in phosphate buffered saline (PBS), pH7.4 (approximately $1 \times 10^{6} \mathrm{CFU} / \mathrm{ml}$, where CFU is colony forming units). Assays were prepared in micro centrifuge tubes and contained approximately $1 \times 10^{5} \mathrm{CFU} / \mathrm{mL}$ of Gram-positive and Gram-negative bacteria with $1 \mu \mathrm{g} / \mathrm{mL}$ ( $1 \%$ DMSO) and $5 \mu \mathrm{g} / \mathrm{mL}$ (5\% DMSO) of $-\mathrm{OH}$ polymer/monomer in phosphate buffered solution (PBS) respectively. The stability of the compound was confirmed in the solvent mixture using its absorption spectra, as shown in Figure S17. For irradiation, $100 \mu \mathrm{L}$ aliquots were transferred to the wells of a 96 well tissue culture plate which was irradiated for 15 minutes using a LED lamp with wavelength $\left(\lambda_{\text {exc. }} \sim 525 \mathrm{~nm}\right)$. For non-irradiated controls, aliquots were transferred to another 96-well plate which was incubated in the dark for 15 minutes. The contents of the wells were then diluted, $1 / 100$ with PBS and $100 \mu \mathrm{l}$ spread onto $\mathrm{MH}$ agar and incubated at $37^{\circ} \mathrm{C}$ overnight before counting colony forming units (CFU). Control assays consisted of non-irradiated samples, addition of only DMSO and without addition of the copolymer.

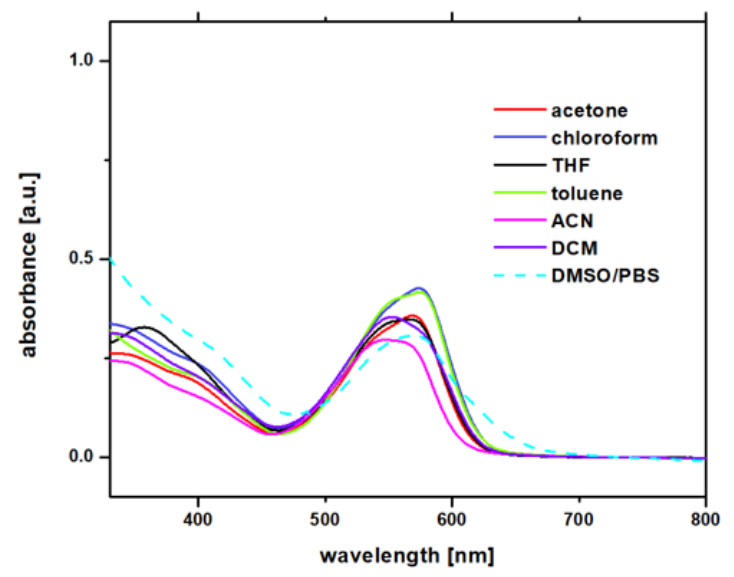

Figure S18. UV-visible absorption spectra of copolymer in a range of solvents; especially depicting the stability of the compound in a DMSO/PBS solvent mixture (cyan colour).

A comparative study on the activity of the copolymer over the monomer were performed. A similar assay as mentioned above was performed and the results are presented in Figure \$19 found below. Only on irradiation of the copolymer and monomer we can observe some bactericidal activity, where the copolymer shows an enhanced activity of $>80 \%$ killing of the gram-positive S.aureus and its 
resistant strain. The monomer shows $<5 \%$ killing for the Gram-positive bacteria whereas $>10 \%$ killing for Gram-negative strain only with the increased concentration of the complex. As we know, Gramnegative bacteria are more resistant to antibiotics than Gram-positive bacteria, because they have an outer cell membrane. We could observe a similar trend for our complexes as it shows around $60-80 \%$ killing for the Gram-negative E.coli strain was observed under higher concentration of the copolymer. The huge leap in the activity of the complex from its monomeric form to copolymer opens up new approaches towards the BODIPY in their polymeric forms.

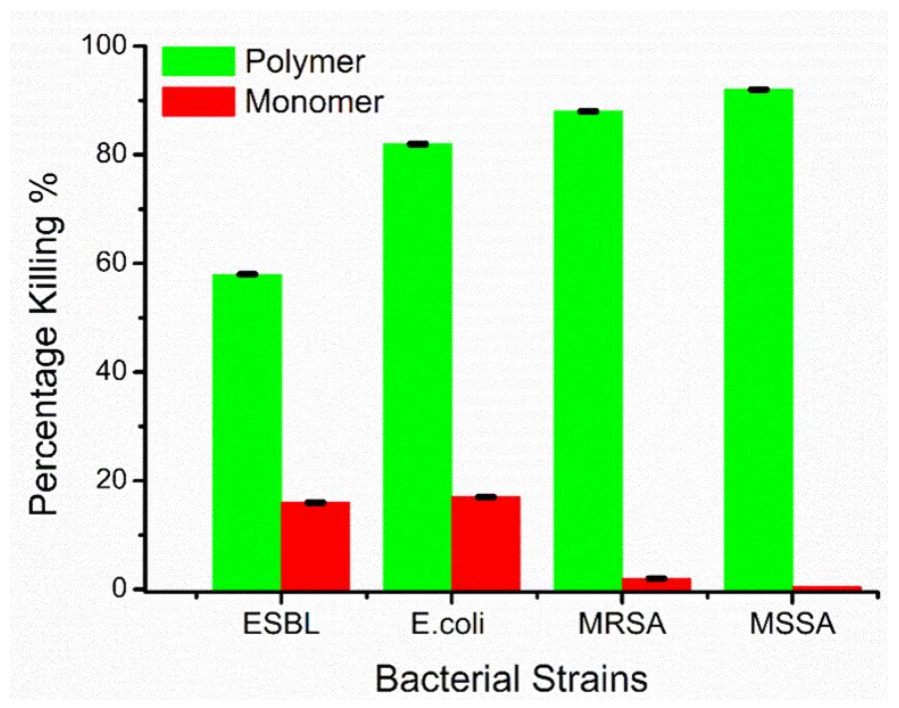

Figure S19. Comparison on the photoactivated bactericidal activity of copolymer and its BODIPY-2H, Conditions: Bacterial strains Staphylococcus aureus (MSSA, ATCC 25923), methicillin-resistant S.aureus (MRSA, ATCC 43300), Esherichia.coli (E.coli, ATCC 25922) and an extended spectrum $\beta$-lactamase (ESBL) producing E.coli (CL11), [copolymer/BODIPY-2H] for

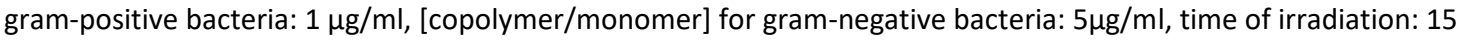
minutes, wavelength of light for irradiation $\lambda \sim 525 \mathrm{~nm}$. 


\section{Cytotoxic study using MTT assay}

\section{Cell lines and Culture conditions}

A human keratinocyte cell line (HaCaT) obtained from the American Type Culture Collection (ATCC) was used. Cells were routinely cultured in Dulbecco's modified Eagle's medium (DMEM) supplemented with $10 \%(\mathrm{v} / \mathrm{v})$ fetal bovine serum (FBS) and maintained at $37^{\circ} \mathrm{C}$ and $5 \% \mathrm{CO}_{2}$ atmosphere. Cells were passaged/harvested by detaching from tissue culture flasks using TrypLE ${ }^{\mathrm{TM}}$ Express (Gibco) for $5-10 \mathrm{~min}$ at $37^{\circ} \mathrm{C}$.

\section{Cell Viability - MTT Assay}

HaCaT cells were seeded in 96-well microtitre plates at a density of $1 \times 10^{5}$ cells $/ \mathrm{ml}$ in $100 \mu \mathrm{l}$ culture medium (DMEM with $10 \%(\mathrm{v} / \mathrm{v}) \mathrm{FBS}$ ) and incubated at $37^{\circ} \mathrm{C}, 5 \% \mathrm{CO}_{2}$ for $48 \mathrm{~h}$ for cell attachment. Plates

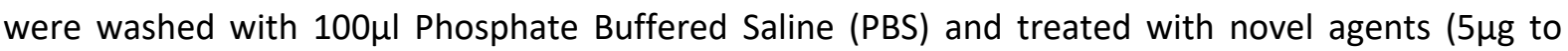
$250 \mu \mathrm{g})$ for $2 \mathrm{~h}$. Control wells were treated with triton X-100 (1\%) instead of test agent. Following treatment, wells were washed with $100 \mu$ PBS before adding $100 \mu$ I DMEM with $10 \%(\mathrm{v} / \mathrm{v}) \mathrm{FBS}$. Plates were incubated at $37^{\circ} \mathrm{C}$ and $5 \% \mathrm{CO}_{2}$ for $24 \mathrm{~h}$. Freshly prepared MTT (3-(4,5-dimethylthiazol-2-yl)-2,5diphenyltetrazolium bromide) ( $100 \mu \mathrm{l}$ of $5 \mathrm{mg} / \mathrm{ml}$ in culture medium without FBS or supplements) was added to each well, followed by incubation for $4 \mathrm{~h}$ at $37^{\circ} \mathrm{C}$ with $5 \% \mathrm{CO}_{2}$. The medium was discarded, and the cells were washed with PBS before adding100 $\mu$ l of MTT fixative solution (isopropanol) and incubating at room temperature with shaking for $4 \mathrm{~min}$. Absorbance at $595 \mathrm{~nm}$ was measured in a Thermo Multiskan Ex plate reader.

\section{Cytotoxicity of OH BODIPY to HaCaT cells}

Measurement of OH BODIPY cytotoxicity to $\mathrm{HaCaT}$ cells using the MTT assay revealed a $\mathrm{IC}_{50}$ value of $45.2 \mu \mathrm{g}$. This is the concentration resulting in the loss of viability of up to $50 \%$ of HaCaT cells. This indicates some cytotoxicity to keratinocytes at concentrations close to those that resulted in $>5 \log$ reduction in Gram-negative and $>3$ log reduction to Gram-positive bacterial colony forming units. 


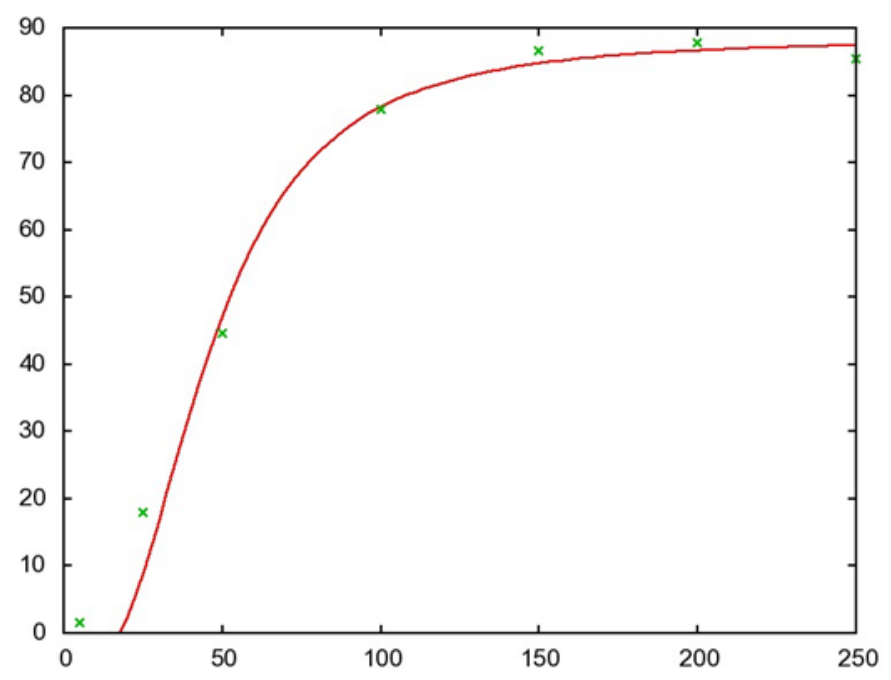

Figure S20. The half maximal inhibitory concentration $\left(\mathrm{IC}_{50}\right)$ curve of $\mathrm{OH}$ copolymer under varied concentration on the keratinocyte $\mathrm{HaCaT}$ cells. 


\section{References}

1 G. M. Greetham, P. Burgos, C. Qian, I. P. Clark, P. S. Codd, R. C. Farrow, M. W. George, M. Kogimtzis, P. Matousek, A. W. Parker, M. R. Pollard, D. A. Robinson, X. Zhi-Jun and M. Towrie, Appl. Spectrosc., 2010, 64, 1311-1319.

2 S. Banfi, G. Nasini, S. Zaza and E. Caruso, Tetrahedron, 2013, 69, 4845-4856.

3 N. Epelde-Elezcano, V. Martínez-Martínez, E. Peña-Cabrera, C. F. A. Gómez-Durán, I. L. Arbeloa and S. Lacombe, RSC Adv., 2016, 6, 41991-41998.

4 Y. Yue, Y. Guo, J. Xu and S. Shao, New J. Chem., 2011, 35, 61-64.

5 T. Matsumoto, Y. Urano, Y. Takahashi, Y. Mori, T. Terai and T. Nagano, J. Org. Chem., 2011, 76, $3616-3625$.

6 T. Ozdemir and F. Sozmen, RSC Adv., 2016, 6, 10601-10605.

7 C. Reichardt, Chem. Rev., 1994, 94, 2319-2358. 